\title{
Real exchange rate dynamics revisited: A case with financial market imperfections
}

\author{
Ippei Fujiwara*, Yuki Teranishi \\ Bank of Japan, 2-1-1 Nihonbashihongokucho, Tokyo 103-8660 Japan
}

JEL classification:

F31

F41

Keywords:

Financial market imperfection

Real exchange rate

Staggered loan contract

\begin{abstract}
A B S T R A C T
In this paper, we investigate the relationship between real exchange rate dynamics and financial market imperfections. For this purpose, we first construct a New Open Economy Macroeconomics (NOEM) model that incorporates staggered loan contracts as a simple form of the financial market imperfections. Our model with such a financial market friction replicates persistent, volatile, and realistic hump-shaped responses of real exchange rates, which have been thought very difficult to materialize in standard NOEM models. Remarkably, these realistic responses can materialize even with both supply and demand shocks, such as cost-push, loan rate, and monetary policy shocks. This implies that the financial market development is a key element for understanding real exchange rate dynamics.
\end{abstract}

(c) 2011 Elsevier Ltd. All rights reserved.

\section{Introduction}

Empirical studies have been showing that real exchange rate dynamics are very volatile, persistent, and hump-shaped against shocks, as shown in Eichenbaum and Evans (1995), Cheung and Lai (2000), Faust and Rogers (2003), and Steinsson (2008). Thus far in international finance, there has been intense debate as to whether theoretical dynamic general equilibrium models can reproduce such realistic exchange rate dynamics. Chari et al. (2002), focusing on the first two features, insist that New Open Economy Macroeconomics (NOEM) models may account for the volatility but not for the persistence to a monetary policy shock. In response to this critique, several studies such as Bergin and Feenstra (2000), G. Benigno (2004), and P. Benigno (2004) have attempted to solve these three puzzles by introducing such features as strategic complementarity, non-optimizing monetary policy, and optimal

\footnotetext{
* Corresponding author.

E-mail addresses: ippei.fujiwara@boj.or.jp (I. Fujiwara), yuuki.teranishi@boj.or.jp (Y. Teranishi).
} 
monetary policy into otherwise standard NOEM models. These newly introduced mechanisms mitigate the persistence puzzle of the real exchange rate dynamics to some extent, but have not yet solved it completely. Actual persistence of real exchange rates is still higher than that simulated in those models. Furthermore, the mechanisms do not explain the significant hump-shaped responses of real exchange rates found in data. Steinsson (2008) stresses the importance of generating hump-shaped responses based on his autoregressive estimation of real exchange rates and shows that realistic levels of volatility, persistence, and hump-shaped responses of real exchange rates can be generated with NOEM models when the cost-push shock is added to the economy, where the home bias is very strong.

Analyses on the role of financial market imperfection for the real exchange rate dynamics, however, are very limited, even though Bernanke et al. (1999) and Christiano et al. (2008) emphasize the role of a financial market imperfection to explain the business cycle tendencies found in data. In this paper, therefore we shed light on a sticky loan rate adjustment as a financial market imperfection for the real exchange rate dynamics. The loan rate stickiness is reported in Slovin and Sushka (1983) and Berger and Udell (1992) for the United States (US), Sorensen and Werner (2006) and Gambacorta (2008) for the euro area, and Bank of Japan $(2007,2009)$ for Japan.

We construct a NOEM model with an explicit role of banks. We incorporate sticky loan interest rate contracts as in Teranishi (2008), which assumes it in the closed economy. ${ }^{2}$ In our model, following Gadanecz (2004), McGuire and Tarashev (2006), and Lane and Milesi-Ferretti (2007, 2008), banks make loans to both domestic and foreign firms. The loan rate stickiness stems from imperfect (monopolistic) competition among banks, importance of which is stressed by Sander and Kleimeier (2004), Gropp et al. (2007), and Gropp and Kashyap (2009).

We first estimate the loan interest rate stickiness for the United Kingdom (UK), the euro area, and Japan. Results show that banks, on average, take three quarters to adjust loan rates in these countries. Then we show that our model with such an estimated loan interest rate stickiness can replicate persistent, volatile, and realistic hump-shaped responses of real exchange rates even with both supplyside disturbances through cost-push and loan rate shocks, and demand-side disturbances through a monetary policy shock. In particular, the fact that we can reproduce such a realistic response via a monetary policy shock merits attention. Previous studies, such as Chari et al. (2002) and Steinsson (2008), demonstrate that it is impossible to produce hump-shaped real exchange rate dynamics with such a shock. These results of hump-shaped real exchange rate dynamics are obtained in our model with sticky prices solely due to staggered loan contracts. Interestingly, by further incorporating the staggered price setting, which has been considered the important element for realistic real exchange rate dynamics in former studies, the hump-shaped real exchange rate dynamics to the monetary policy shock disappear. We also show that the welfare cost stemming from such staggered loan contracts is not very large.

This paper is structured as follows. In the next section, we show the outline of the model. In Section 3 , after a brief survey of previous studies related to sticky loan rates, we estimate the degree of loan rate stickiness for the euro area, the UK, and Japan. Section 4 shows that realistic responses of real exchange rates are produced in our model with staggered loan contracts. We also discuss the case with the staggered price in addition to staggered loan setting and the size of the welfare cost stemming from these frictions. Finally, Section 5 summarizes the findings in this paper.

\section{Model}

The model consists of two symmetric countries. There are four types of agents in each country, household, firm, private bank, and the central bank as shown in Fig. 1. In this section, we only show the outline of the model. A detailed derivation of the model is shown in Appendix A.

\footnotetext{
${ }^{1}$ The importance of reproducing the hump-shaped responses are emphasized in, for example, Chrsitiano and Vigfusson (2003) and Gust and Vigfusson (2009).

${ }^{2}$ Graham and Wright (2007) also incorporate sticky loan interest rates into a closed economy general equilibrium model. Contrary to Teranishi (2008), stickiness in interest rates is imposed for consumers in Graham and Wright (2007). Thus, the loan interest rate in the IS curve is sticky in Graham and Wright (2007), while that in the Phillips curve is sticky in our model.
} 


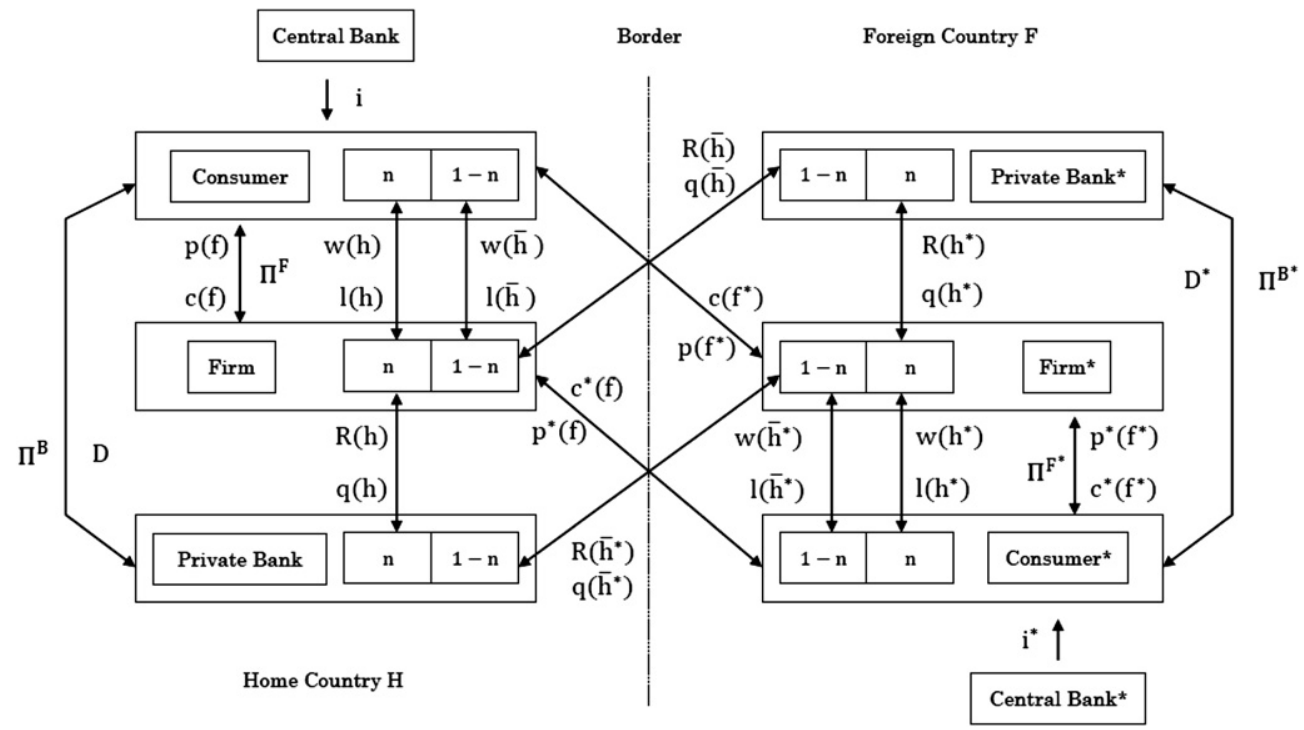

Fig. 1. Consumer, private Bank, Central Bank, and Firm.1 i: nominal deposit interest rate; $c(f)$ : goods produced by firm $\mathrm{f}$ in home country and consumed in home country; $p(\mathrm{f})$ : price of $c(\mathrm{f}) ; l(\mathrm{~h})$ : labor type h supplied from the DFS group in home country; $w(\mathrm{~h})$ : nominal wage for $l(\mathrm{~h}) ; l(\bar{h})$ : labor type $\bar{h}$ supplied from the IFS group in home country; $w(\bar{h})$ : nominal wage for $1(\bar{h})$; D: amount of deposits at private banks in home country; $\Pi^{\mathrm{B}}$ : nominal dividend stemming from ownership of both local and international banks in home country; $q(\mathrm{~h})$ : amounts of loan borrowed by firm $\mathrm{f}$ in home country to hire labor type $\mathrm{h}$ in DFS group from local bank $\mathrm{h}$ in home country; $R(\mathrm{~h})$ : gross loan rate applied for $q(\mathrm{~h}) ; c^{*}(\mathrm{f})$ : goods produced by firm $\mathrm{f}$ in home country and consumed in foreign country; $\mathrm{p}^{*}$ (f) : price of $c^{*}(\mathrm{f}) ; q(\bar{h})$ : amounts of loan borrowed by firm f in home country to hire labor type $\overline{\mathrm{h}}$ in IFS group from international bank $\mathrm{h}$ in foreign country; $R(\bar{h})$ : gross loan rates applied for $q(\bar{h})$; * denotes foreign variables.

Firms decide the amount of differentiated labor to be employed from both the domestically financially supported (DFS) and the internationally financially supported (IFS) groups. Part of the costs of labor must be financed by external loans from banks. For example, in the domestic country, to finance the costs of hiring workers $l_{t}(h)$ from the DFS group for the DFS project, the firm must borrow from local bank $h$ in the home country. On the other hand, to finance the costs of hiring workers $l_{t}(\bar{h})$ from the IFS group for the IFS project, the firm must borrow from international bank $\bar{h}$ in the foreign country.

This setting reflects the fact that financial markets are globally integrated. As shown in Gadanecz (2004), McGuire and Tarashev (2006), and Lane and Milesi-Ferretti (2007, 2008), a significant increase has taken place in international borrowing and lending. We also know by looking into actual project finance that firms borrow funds with many different loan interest rates at the same time, depending on the nature of the projects. Firms tend to face different loan rates depending on when, why, for what, how long, or how much they require external funds. We interpret that these project differences are characterized by types of labor. ${ }^{3}$

\subsection{Household}

The economy is assumed to be populated by a large representative family. A representative consumer in the home country maximizes the following welfare $W_{t}$ :

\footnotetext{
${ }^{3}$ Kobayashi (2008) assumes a one-to-one relation between a firm and a bank due to monopoly. Mandelman (2010) supposes a situation where each project factory in one region is forced to borrow from a neighbor bank by information or geographical segmentation in the bank evaluating the project. Both produce the same loan rate curve as in our model.
} 


$$
W_{t}=E_{t} \sum_{T=t}^{\infty} \beta^{T-t}\left[u\left(C_{T}\right)-v\left(l_{h, T}\right)-v\left(l_{\bar{h}, T}\right)\right] .
$$

$\mathrm{E}_{t}$ is the expectation operator conditional on the state of nature at date $t . u(\cdot)$ is an increasing and concave function in the aggregate consumption index $C_{t}$, and $v(\cdot)$ is an increasing and convex function in the total number of hours. Following Schmitt-Grohé and Uribe (2007), the total number of hours allocated first to the labor union and then to the different labor markets. ${ }^{4}$ They are denoted by $l_{h, T}$ and $l_{\bar{h}, T}$, must satisfy

$$
l_{h, t}=\frac{1}{n} \int_{0}^{n} l_{t}(h) d h
$$

and

$$
l_{\bar{h}, t}=\frac{1}{1-n} \int_{n}^{1} l_{t}(\bar{h}) d \bar{h} .
$$

Consequently, there exists no wage heterogeneity within each group. Household preferences are defined over per capita variables. A representative household's maximization is subject to (1) the budget constraint, (2) the labor demands, and (3) the relationship between the aggregate homogenous labor effort in the goods market and the aggregate household employment.

The budget constraint is given by

$$
P_{t} C_{t}+E_{t}\left[X_{t, t+1} B_{t+1}\right]+D_{t} \leq B_{t}+\left(1+i_{t-1}\right) D_{t-1}+\int_{0}^{n} w_{t}(h) l_{t}(h) d h+\int_{n}^{1} w_{t}(\bar{h}) l_{t}(\bar{h}) d \bar{h}+\Pi_{t}^{B}+\Pi_{t}^{F},
$$

where $P_{t}$ is the aggregate price level, $B_{t}$ is a set of risky assets, $D_{t}$ is the deposit to private banks, $i_{t}$ is the nominal deposit interest rate set by the central bank from $t-1$ to $t, w_{t}(h)$ is the nominal wage for $l_{t}(h)$, $w_{t}(\bar{h})$ is the nominal wage for $l_{t}(\bar{h}), \Pi_{t}^{B}=\int_{0}^{1} \Pi_{t-1}^{B}(h) \mathrm{d} h$ is the nominal dividend stemming from the ownership of both local and international banks in the home country, $\Pi_{t}^{F}=\int_{0}^{1} \Pi_{t-1}^{F}(f) \mathrm{d} f$ is the nominal dividend from the ownership of the firms in the domestic country, and $X_{t, t+1}$ is the stochastic discount factor. Because we assume a complete financial market between two countries, consumers in each country can internationally trade the state contingent securities to insure against country specific shocks. Consequently, there exists a unique discount factor.

The labor demands are derived from firms' cost minimization problem in the next subsection. After integrating over domestic firms, they are given by

$$
l_{t}(h)=\frac{1}{n}\left[\frac{R_{t}(h) w_{t}(h)}{\Omega_{h, t}}\right]^{-\epsilon} L_{h, t},
$$

and

$$
l_{t}(\bar{h})=\frac{1}{1-n}\left[\frac{R_{t}(\bar{h}) w_{t}(\bar{h})}{\Omega_{\bar{h}, t}}\right]^{-\epsilon} L_{\bar{h}, t},
$$

where $R_{t}(h)$ and $R_{t}(\bar{h})$ denote the gross loan rates applied for the DFS and IFS projects. $\Omega_{h, t}$ and $\Omega_{\bar{h}, t}$ are nominal marginal costs for the DFS and IFS projects.

The final constraint is the relationships between the aggregate homogenous labor effort in the goods market $L_{h, t}$ and $L_{\bar{h}, t}$ and aggregate household employment $l_{h, t}$ and $l_{\bar{h}, t}$, that can be derived by integrating Equations (3) and (4) above over differentiated labor supply

\footnotetext{
4 This is necessary to obtain nonlinear equilibrium conditions. For the discussion on this point, see Schmitt-Grohé and Uribe (2006).
} 


$$
l_{h, t}=L_{h, t} \frac{1}{n} \int_{0}^{n}\left[\frac{R_{t}(h) w_{t}(h)}{\Omega_{h, t}}\right]^{-\epsilon} d h,
$$

and

$$
l_{\bar{h}, t}=L_{\bar{h}, t} \frac{1}{1-n} \int_{n}^{1}\left[\frac{R_{t}(\bar{h}) w_{t}(\bar{h})}{\Omega_{\bar{h}, t}}\right]^{-\epsilon} d h .
$$

The consumption index that consists of bundles of differentiated goods produced by home and foreign firms is defined as

$$
C_{t} \equiv \frac{C_{H, t}^{\phi} C_{F, t}^{1-\phi}}{\phi^{\phi}(1-\phi)^{1-\phi}},
$$

where $\phi(0 \leq \phi \leq 1)$ is a preference parameter that expresses the home bias. Here, $C_{H, t}$ and $C_{F, t}$ are consumption subindices of the continuum of differentiated goods produced by firms in the home country and the foreign country, respectively. They are defined as

$$
C_{H, t} \equiv\left[\int_{0}^{1} c_{t}(f) \frac{\sigma-1}{\sigma} d f\right]^{\frac{\sigma}{\sigma-1}},
$$

and

$$
C_{F, t} \equiv\left[\int_{0}^{1} c_{t}\left(f^{*}\right) \frac{\sigma-1}{\sigma} d f^{*}\right]^{\frac{\sigma}{\sigma-1}},
$$

where $c_{t}(f)$ is the demand for a good produced by firm $f$ in the home country and $c_{t}\left(f^{*}\right)$ is the demand for a good produced by a firm $f^{*}$ in the foreign country, where the asterisk $*$ denotes foreign variables.

Similarly, the consumption index in the foreign country is given by

$$
C_{t}^{*} \equiv \frac{\left(C_{H, t}^{*}\right)^{1-\phi}\left(C_{F, t}^{*}\right)^{\phi}}{(1-\phi)^{1-\phi} \phi^{\phi}} .
$$

There exists no trade friction and consumers in both countries have the same preferences over differentiated goods.

\subsection{Firm}

Firms in both home and foreign countries optimally hire differentiated labor as price (wage) takers. The domestic firm $f$ hires all types of labor from both the DFS and the IFS groups. When hiring from the DFS group, $\bar{\gamma}$ portion of the labor cost associated with labor type $h$ is financed by borrowing from the local bank $h$. Then, the first-step cost minimization problem on the allocation of differentiated labor from the DFS group is to minimize

$$
\int_{0}^{n}\left[1+\bar{\gamma} r_{t}(h)\right] w_{t}(h) l_{t}(h, f) d h,
$$

subject to the sub-index $L_{h, t}(f)$ regarding the labor from the DFS group to firm $f$ :

$$
L_{h, t}(f) \equiv\left[\left(\frac{1}{n}\right)^{\frac{1}{\epsilon}} \int_{0}^{n} l_{t}(h, f) \frac{\epsilon-1}{\epsilon} d h\right]^{\frac{\epsilon}{\epsilon-1}}
$$


where $r_{t}(h)$ is the net loan interest rate applied to employ a particular labor type $h$ applied to differentiated labor supply. $l_{t}(h, f)$ denotes the labor type $h$ employed by the firm $f$. Without loss of generality, Equation (10) can be represented with the gross interest rate $R_{t}(h)$ with appropriate $\gamma$ as

$$
\int_{0}^{n} \gamma R_{t}(h) w_{t}(h) l_{t}(h, f) d h
$$

As shown in Appendix A, the size of $\gamma$ does not affect the prices and allocations for the endogenous variables of our interests. The local bank $h$ maintains some monopoly power over setting loan interest rates. We have a similar problem for the IFS group through borrowing from the international bank $\bar{h}$ in the foreign country.

Because firms have a preference $n$ to hire workers from the DFS group and $(1-n)$ to hire workers from the IFS group, the cost minimization problem describing the allocation of differentiated labor between these two groups is also given by minimizing

$$
\Omega_{h, t} L_{h, t}(f)+\Omega_{\bar{h}, t} L_{\bar{h}, t}(f),
$$

subject to the aggregate labor index:

$$
L_{t}(f) \equiv \frac{L_{h, t}(f)^{n} L_{\bar{h}, t}(f)^{1-n}}{n^{n}(1-n)^{1-n}},
$$

where $\Omega_{h, t}$ is the Lagrange multiplier on the constraint (11) in the cost minimization problem, while $\Omega_{\bar{h}, t}$ is that for a similar problem for workers from the IFS group. We here assume a linear production technology:

$$
y_{t}(f)=\exp \left(z_{t}\right) L_{t}(f),
$$

where $z_{t}$ denotes the technology shock to the domestic production.

A firm $f$ facing the Calvo (1983) - Yun (1996) type friction with probability $(1-\alpha)$ resets its domestic and foreign prices $p_{t}(f)$ and $p_{t}^{*}(f)$ separately under the pricing-to-market assumption to maximize

$$
E_{t} \sum_{T=t}^{\infty} \alpha^{T-t} X_{t, T}\left[p_{t}(f) c_{T}(f)+S_{T} p_{t}^{*}(f) c_{T}^{*}(f)-\Omega_{T} L_{T}(f)\right]
$$

where $S_{t}$ denotes the nominal exchange rate and $\Omega_{T}$ denotes the nominal marginal cost. It should be noted that price setting is independent of the loan interest rate setting of private banks.

\subsection{Private bank}

We here only describe the optimization problem of an international bank in the home country since it is the most complicated. The international bank takes on the exchange rate risk inherent in its loans. Similarly to the price setting, each international bank can reset loan interest rates with probability $(1-\psi)$ following the Calvo (1983) - Yun (1996) framework. Under the segmented environment caused by differences in labor supply, private banks can set different loan interest rates depending on the types of labor. As a consequence, the private bank holds some monopoly power over the loan interest rate to firms. The international bank $\bar{h}^{*}$ in the domestic country chooses the loan interest rate $\tilde{R}_{t}\left(\bar{h}^{*}\right)$ to maximize the present discounted value of profit:

$$
E_{t} \sum_{T=t}^{\infty} \psi^{T-t} X_{t, T} q_{T}\left(\bar{h}^{*}, f^{*}\right)\left[R_{t}\left(\bar{h}^{*}\right)-\frac{S_{T}}{S_{T+1}}\left(1+i_{T}\right)\right]
$$

where $q_{t}\left(\bar{h}^{*}, f^{*}\right)$ denotes the amounts of loan borrowed by firm $f^{*}$ to the labor types $\bar{h}^{*}$. 


\subsection{Central bank}

We assume Taylor (1993) - type rules for monetary policy:

$$
1+i_{t}=\left(1+i_{t-1}\right)^{\rho_{i}}\left(\frac{1}{\beta}\right)^{1-\rho_{i}}\left(\frac{P_{t}}{P_{t-1}}\right)^{\left(1-\rho_{i}\right) \Phi_{1}}\left(\frac{C_{t}}{C}\right)^{\left(1-\rho_{i}\right) \Phi_{2}} \exp \left(\nu_{t}\right)
$$

and

$$
1+i_{t}^{*}=\left(1+i_{t-1}^{*}\right)^{\rho_{i}}\left(\frac{1}{\beta}\right)^{1-\rho_{i}}\left(\frac{P_{t}^{*}}{P_{t-1}^{*}}\right)^{\left(1-\rho_{i}\right) \Phi_{1}}\left(\frac{C_{t}^{*}}{C^{*}}\right)^{\left(1-\rho_{i}\right) \Phi_{2}},
$$

where $C$ denotes the steady state consumption level. $\Phi_{1}, \Phi_{2}$, and $\rho_{i}$ are positive policy parameters.

\subsection{Linearized equilibrium conditions}

By log-linearly approximating the equilibrium conditions obtained from above problems around the steady states, we can derive linearized equilibrium conditions. ${ }^{5}$ Here, $\hat{A}_{t} \approx \log \left(\frac{A_{t}}{A}\right) \approx \frac{A_{t}-A}{A}$, where $A$ is the steady state of $A_{t}$.

Aggregate consumption in each country is given by

$$
\hat{C}_{t}=E_{t} \hat{C}_{t+1}-\frac{1}{v}\left(\tilde{l}_{t}-E_{t} \hat{\pi}_{t+1}\right),
$$

and

$$
\hat{C}_{t}^{*}=E_{t} \hat{C}_{t+1}^{*}-\frac{1}{v}\left(\tilde{l}_{t}^{*}-E_{t} \hat{\pi}_{t+1}^{*}\right) .
$$

$\pi_{t}\left(\pi_{t}^{*}\right)$ denotes home (foreign) consumer price index (CPI) inflation and $v$ is the coefficients of the relative risk aversion. $\tilde{i}_{t}$ is the difference of nominal interest rate from its steady state value. The price setting equations in the home and foreign countries are given by

$$
\hat{\pi}_{t}=\beta E_{t} \hat{\pi}_{t+1}+\frac{(1-\alpha \beta)(1-\alpha)}{\alpha}\left\{\begin{array}{l}
\phi\left[n \hat{R}_{h, t}+(1-n) \hat{R}_{\bar{h}_{, t}}\right] \\
+(1-\phi)\left[(1-n) \hat{R}_{h^{*}, t}+n \hat{R}_{\bar{h}_{, t}}\right] \\
+\phi v \hat{C}_{t}+(1-\phi) v \hat{C}_{t}^{*}+(1-\phi) \hat{e}_{t}+\phi\left(a_{t}-z_{t}\right)
\end{array}\right\}
$$

and

$$
\hat{\pi}_{t}^{*}=\beta E_{t} \hat{\pi}_{t+1}^{*}+\frac{(1-\alpha \beta)(1-\alpha)}{\alpha}\left\{\begin{array}{l}
\phi\left[(1-n) \hat{R}_{h^{*}, t}+n \hat{R}_{\bar{h}^{*}, t}\right] \\
+(1-\phi)\left[n \hat{R}_{h, t}+(1-n) \hat{R}_{\bar{h}, t}\right] \\
+\phi v \hat{C}_{t}^{*}+(1-\phi) v \hat{C}_{t}-(1-\phi)\left(\hat{e}_{t}+z_{t}\right)
\end{array}\right\}
$$

An international perfect risk-sharing condition implies

$$
\frac{1}{v} \hat{e}_{t}=\hat{C}_{t}-\hat{C}_{t}^{*}+x_{t}
$$

Here $\hat{R}_{h, t}\left(\hat{R}_{h^{*}, t}\right)$ denotes the loan rate offered by a home local (foreign international) bank to a home firm, $\hat{R}_{h^{*}, t}\left(\hat{R}_{\vec{h}^{*}, t}\right)$ denotes the loan rate offered by a home international (foreign local) bank to a foreign

\footnotetext{
${ }^{5}$ For nonlinear model and conditions, see Appendix A.
} 
firm, $\hat{e}_{t}$ denotes the real exchange rate, $a_{t}$ denotes the cost-push shock to $p_{t}(f)$, and $x_{t}$ denotes the UIP shock, importance of which is stressed by Lubik and Schorfheide (2005). As shown in Steinsson (2008), the cost-push shock plays an important role in determining the dynamics of the real exchange rate, which will be explained later. When there is no loan contract, Equations (21) and (22) are reduced to standard international new Keynesian Phillips curves.

The (new Keynesian) loan supply curves in both countries are

$$
\begin{aligned}
& \hat{R}_{\bar{h}^{*}, t}=\frac{\psi}{1+\psi^{2} \beta}\left[\hat{R}_{\bar{h}^{*}, t-1}+\beta E_{t} \hat{R}_{\bar{h}^{*}, t+1}+\frac{(1-\psi \beta)(1-\psi)}{\psi} \tilde{l}_{t}^{*}\right], \\
& \hat{R}_{h, t}=\frac{\psi}{1+\psi^{2} \beta}\left[\hat{R}_{h, t-1}+\beta E_{t} \hat{R}_{h, t+1}+\frac{(1-\psi \beta)(1-\psi)}{\psi}\left(\tilde{l}_{t}+m_{t}\right)\right], \\
& \hat{R}_{\bar{h}, t}=\frac{\psi}{1+\psi^{2} \beta}\left[\hat{R}_{\bar{h}, t-1}+\beta E_{t} \hat{R}_{\bar{h}, t+1}+\frac{(1-\psi \beta)(1-\psi)}{\psi} \tilde{l}_{t}\right],
\end{aligned}
$$

and

$$
\hat{R}_{h^{*}, t}=\frac{\psi}{1+\psi^{2} \beta}\left[\hat{R}_{h^{*}, t-1}+\beta E_{t} \hat{R}_{h^{*}, t+1}+\frac{(1-\psi \beta)(1-\psi)}{\psi} \tilde{l}_{t}^{*}\right] .
$$

Here $m_{t}$ is the loan rate shock for the loan rate set by the home local banks for home firms. In Cúrdia and Woodford (2010) and Gerali et al. (2010), the loan rate shock comes from a default risk and a risk premium for the borrower. ${ }^{6}$ The reason why these loan rate curves include lags is as follows: The loan rate itself is like the price level; If the new Keynesian Phillips curve is expressed in terms of the price level rather than inflation rates, it must contain the lagged price level. Since the marginal cost is a function of the loan rate, its dynamics are also affected by the lagged loan rate.

The rest are the policy rules:

$$
\tilde{l}_{t}=\rho_{i} \tilde{l}_{t-1}+\left(1-\rho_{i}\right) \Phi_{1} \hat{\pi}_{t}+\left(1-\rho_{i}\right) \Phi_{2} \hat{C}_{t}+\nu_{t}
$$

and

$$
\tilde{l}_{t}=\rho_{i} \tilde{l}_{t-1}+\left(1-\rho_{i}\right) \Phi_{1} \hat{\pi}_{t}^{*}+\left(1-\rho_{i}\right) \Phi_{2} \hat{C}_{t}^{*} .
$$

Here $v_{t}$ is a monetary policy shock in the home country, which is used in the analysis by Chari et al. (2002) for the dynamics in the real exchange rates.

We have 11 equations, namely, Equations (19)-(29), for 11 endogenous variables: $\hat{C}_{t}, \hat{C}_{t}^{*}, \hat{\pi}_{t}, \hat{\pi}_{t}^{*}, \hat{e}_{t}$, $\hat{R}_{\bar{h}^{*}, t}, \hat{R}_{h, t}, \hat{R}_{\bar{h}, t}, \hat{R}_{h^{*}, t}, \tilde{i}_{t}$, and $\tilde{i}_{t}^{*}$.

\section{Empirical evidence for sticky loan rates}

Stickiness in loan rates has been reported regardless of newly contracted or outstanding and shortor long-term contracts. For the US, using micro-data, Slovin and Sushka (1983) show that it takes two or more quarters for private banks to adjust loan rates even for newly contracted loans against changes in the market rate. This finding is consistent with the results in Berger and Udell (1992). For the euro area countries, Sorensen and Werner (2006) estimate the incompleteness in the pass-through from policy rates to loan rates via an error correction model using macro-data. They find the lags ranging between one and three quarters even for newly contracted long-term loans. Gambacorta (2008)

\footnotetext{
${ }^{6}$ Recent studies such as Neumeyer and Perri (2005) and Uribe and Yue (2006) insist that international risk premium shocks can induce large business cycles. In addition, according to Marston (1995) and Uribe and Yue (2006), dynamics in interest rate spreads are quite persistent.
} 
conducts a similar analysis for Italy and shows the existence of sticky adjustment in loan rates for about two quarters for newly contracted short-term lending. For Japan, Bank of Japan (2007, Figure 50) reports that the major city banks need more than three quarters and local banks need more than five quarters to adjust their loan rates to a change in the policy rate. Similarly, Bank of Japan (2009, Figs. 312) concludes that loan rates demonstrate considerable stickiness. Several reasons are also reported for the existence of the sticky loan interest rates. Sorensen and Werner (2006), Sander and Kleimeier (2004), and Gropp et al. (2007) claim that the lower degree of competition can induce a higher degree of loan rate stickiness. Less competition gives banks the ability to benefit through sluggish adjustment of the lending rate. On the other hand, Berger and Udell (1992) emphasize relationship banking, insisting that long-run (repeated) business relations between banks and firms can result in loan rate stickiness. The banks set lower interest rates to insure that risk-averse borrowers in a longrun relationship avoid bankruptcy when interest rates are high. In this paper, we take the former view when modeling the loan rate stickiness.

To understand the real exchange rate dynamics in our model, we need to obtain the parameters on the loan rate stickiness. We estimate the Calvo parameter implicit in the new Keynesian loan rate curve in Equation (25) by nonlinear maximum likelihood estimation for the UK, the euro area, and Japan. When estimating the Calvo parameters, we assume that the same loan rate stickiness should apply for both domestic and international lending. We use official policy rates provided by central banks. For the UK, we use the official bank rate and weighted average overdraft interest rate for non-financial corporations for the period from January 1999 to March 2009; for the euro area, we use the main refinancing operations fixed rate and average outstanding loan interest rate from banks for nonfinancial corporations from the monetary financial institution (MFI) interest rate statistics for the period from January 2003 to March 2009; for Japan, we use the overnight uncollateralized call rate and average stock loan interest rate for the period from January 1984 to December $1995 .{ }^{7}$ All data are monthly average and are de-trended by the HP filter with the smoothing parameter 14,400 , which is usually used for monthly data. For a forward (expected) variable, we use the one-period-ahead forecast obtained from an estimated AR(2) model.

Table 1 reports the values of the Calvo parameters on a quarterly basis. Similar values are obtained for all three areas. On average, since the Calvo parameter on a quarterly basis is very close to 0.66 , the loan interest rates are adjusted by about three quarters in each country. These findings are consistent with the former empirical studies. In the next section, we examine the responses of the real exchange rate to structural shocks under the estimated parameters of sticky loan rates in this section.

\section{Simulation}

The parameters are calibrated as in Table 2. $\beta, v, \alpha, \sigma, n, \phi, \Phi_{1}, \Phi_{2}$, and $\rho_{i}$ are from Steinsson (2008), $\epsilon$ and $\epsilon^{*}$ are from Rotemberg and Woodford (1997), and $\psi$ is the estimated average value of loan rate stickiness across the countries in Table 1 . We examine four types of positive shocks. ${ }^{8}$ They are cost-push $\left(a_{t}\right)$, loan rates $\left(m_{t}\right)$, UIP $\left(x_{t}\right)$, and monetary policy $\left(\nu_{t}\right)$ shocks. Following Steinsson (2008), we set that each shock follows $\operatorname{AR}(1)$ process with a parameter of 0.9 . We first show the case with flexible price setting, and then with the infrequent price setting. Finally, we show the size of the welfare cost in consumption unit by incorporating either price or loan rigidities.

\subsection{Dynamics under flexible price setting}

We first show the simulation results when the prices are flexible. With $\alpha=0$, Equations (21) and (22) are transformed into

\footnotetext{
${ }^{7}$ For the UK and the euro area, we use the whole sample available, but for Japan we only use the data until the end of 1995 to avoid a policy period of virtually zero interest rates.

${ }^{8}$ Since we here simulate the linearized model, the size of the shocks does not matter in understanding the dynamics of the real exchange rate in Tables 3 and 4.
} 
Table 1

Estimation result (quarter basis).

\begin{tabular}{lll}
\hline Country & Mean & $\pm \sigma$ interval \\
\hline UK & 0.59 & {$[0.45,0.74]$} \\
Euro area & 0.57 & {$[0.55,0.58]$} \\
Japan & 0.57 & {$[0.56,0.59]$} \\
Average & 0.58 & - \\
\hline
\end{tabular}

We estimate the Calvo parameter implicit in Equation (26) using nonlinear maximum likelihood estimation. For the UK, we use the official bank rate and weighted average overdraft interest rate for non-financial corporations for the period from January 1999 to March 2009. For the euro area, we use the main refinancing operations fixed rate and average outstanding loan interest rate from banks for non-financial corporations from the MFI interest rate statistics for the period from January 2003 to March 2009. For Japan, we use the overnight uncollateralized call rate and average stock loan interest rate for the period from January 1984 to December 1995. All data are the monthly average and are de-trended by the HP filter with the conventional parameter 14,400, which is usually used for monthly data. For a forward (expected) variable, we use the one-period-ahead forecast obtained from an estimated AR(2) model.

$$
\begin{aligned}
0= & \phi\left[n \hat{R}_{h, t}+(1-n) \hat{R}_{\bar{h}, t}\right]+(1-\phi)\left[(1-n) \hat{R}_{h^{*}, t}+n \hat{R}_{\bar{h}^{*}, t}\right]+\phi v \hat{C}_{t}+(1-\phi) v \hat{C}_{t}^{*}+(1-\phi) \hat{e}_{t} \\
& +\phi\left(a_{t}-z_{t}\right),
\end{aligned}
$$

and

$$
0=\phi\left[(1-n) \hat{R}_{h^{*}, t}+n \hat{R}_{\bar{h}^{*}, t}\right]+(1-\phi)\left[n \hat{R}_{h, t}+(1-n) \hat{R}_{\bar{h}, t}\right]+(1-\phi) v \hat{C}_{t}+\phi v \hat{C}_{t}^{*}-(1-\phi)\left(\hat{e}_{t}+z_{t}\right) .
$$

Table 3 shows the detailed simulation outcomes of the real exchange rate dynamics for the home shocks under flexible price setting. We report five statistics defining the real exchange rate dynamics: (1) UL (up-life); (2) UL/HL (up-life over half-life); (3) QL-HL (quarter-life minus half-life); (4) AR(1) persistence; and (5) relative standard deviation of real exchange rates to consumption. ${ }^{9}$ UL denotes the duration until the impulse response falls below the top (maximum) point, while HL shows the duration until the impulse response falls below half of the top point. QL denotes the duration until the impulse response falls below a quarter of the top point. These are the measures for how the impulse response functions are hump-shaped. For example, if the impulse responses are monotonically decreasing, UL and UL/HL should be zero. If the impulse responses demonstrate persistent hump-shaped dynamics, $\mathrm{UL} / \mathrm{HL}$ and QL-HL become larger. For comparison, we also examine the case with flexible loan contracts $(\psi=0)$.

The results are shown in Table $3 .^{10}$ The first row in the table reports the average of key empirical features of real exchange rates for the UK, the euro area, and Japan shown in Steinsson (2008). The second to fifth rows illustrate outcomes from the model simulation when loan rates are flexible. These results demonstrate that the model can replicate neither hump-shaped dynamics of the real exchange rate nor $A R(1)$ persistence when both the loan rate and price are flexible. On the other hand, the sixth to ninth rows show outcomes when banks cannot change loan interest rates every period. We can see that the hump-shaped dynamics of the real exchange rates can materialize for both loan rate and monetary policy shocks. In particular, it is worth mentioning that we can reproduce hump-shaped and persistent responses to the monetary policy shock, given the fact that it has been considered very difficult (see, for example, Chari et al., 2002 and Steinsson, 2008). Other statistics, namely, AR(1) persistence and the relative standard deviation of real exchange rates compared to that of consumption, are also in line with the empirical values with these two shocks.

\footnotetext{
${ }^{9}$ As explained in Steinsson (2008), our model cannot replicate the low correlation of consumption between home and foreign countries, since we maintain a complete financial market for consumers.

${ }^{10}$ We show impulse responses for loan rate shocks in Appendix B.
} 
Table 2

Parameter values.

\begin{tabular}{lll}
\hline Parameters & Values & Explanation \\
\hline$\beta$ & 0.99 & Subjective discount factor \\
$v$ & 5 & Coefficient of relative risk aversion ect to real interest rate \\
$\eta$ & 0 & Elasticity of marginal disutility for labor \\
$\alpha$ & 0 or 0.75 & 1-probability of price change \\
$\psi$ & 0.58 & 1-probability of loan interest rate change \\
$\sigma$ & 7.66 & Substitutability of differentiated consumption goods \\
$\epsilon$ & 7.66 & Substitutability of differentiated labor \\
$n$ & 0.5 & Preference for labors in the DFS group \\
$\phi$ & 0.94 & Preference for goods produced in the home country \\
$\Phi_{1}$ & 2 & Coefficient on inflation rate in the Taylor rule \\
$\Phi_{2}$ & 0.5 & Coefficient on the output gap in the Taylor rule \\
$\rho_{i}$ & 0.85 & Lag parameter in the Taylor rule \\
\hline
\end{tabular}

The reason for the hump-shaped dynamics reflects the fact that the real exchange rate dynamics depend crucially on the marginal costs. To see this, we transform Equations (30) and (31) into

$$
0=(2 \phi-1)\left[n\left(\hat{R}_{h, t}-\hat{R}_{\bar{h}^{*}, t}\right)+(1-n)\left(\hat{R}_{\bar{h}, t}-\hat{R}_{h^{*}, t}\right)\right]+\hat{e}_{t}-v(2 \phi-1) x_{t},
$$

where we use Equation (23) and assume neither technology nor cost-push shocks. This equation simply implies that the real exchange rate dynamics depend on the loan rate dynamics. When loan rates are sticky, the loan rate dynamics are hump-shaped thanks to the lags of loan rates in Equations (24)-(27) against loan rate shocks. This directly results in the hump-shaped real exchange rate dynamics. The monetary policy shock also produces such dynamics since the policy rate works as a shock in the loan rate curves. Moreover, the lag in the monetary policy rule further enhances the hump-shapedness of the loan rate dynamics. ${ }^{11}$ Note that the parameters on the first term on the righthand side of Equation (32) implies the role of the home bias. When there is no home bias, namely, $\phi=.5$, hump-shaped responses of real exchange rates cannot be created.

We observe that the hump-shaped responses do not appear for the cost-push shock. This will also become clear from Equation (32). The cost-push shock directly affects the real exchange rate and does not work through the loan rate adjustments. For the UIP shock, loan rates applied to the home country move exactly in a manner opposite to those of the foreign country. Therefore, the UIP shock can be considered as the same scale but the different sign of monetary policy shocks to home and foreign countries, respectively. As a result, we have

$$
\hat{e}_{t}=v(2 \phi-1) x_{t}
$$

Thus, the real exchange rate dynamics are solely determined by the UIP shock.

\subsection{Dynamics under infrequent price setting}

How can the results obtained in the previous section be altered by the introduction of the staggered price setting in addition to the staggered loan contracts examined before? ${ }^{12}$

Table 4 shows the simulation outcomes from the model under both staggered price and loan contracts. The second to the fifth rows illustrate outcomes from the model when loan rates are flexible. On the other hand, the sixth to ninth rows show outcomes when both firms and banks cannot change goods prices and loan interest rates every period, respectively. We can see that the real exchange rate dynamics are humpshaped only with cost-push and loan rates shocks irrespective of whether the loan rates are sticky or not.

\footnotetext{
${ }^{11} \hat{R}_{h, t}, \hat{R}_{\bar{h}^{*}, t}$ and $\bar{l}_{t}$ together with the UIP condition $\left(E_{t} \Delta \hat{S}_{t+1}=\bar{l}_{t}-\bar{l}_{t}^{*}\right)$ are the key elements to understand the hump-shaped dynamics of real exchange rates.

12 Note that even the model without the staggered price setting as above can produce inflation persistence thanks to the dynamics in the marginal cost.
} 
Table 3

Properties of real exchange rate under flexible price.

\begin{tabular}{lllllc}
\hline Setting & HL & UL/HL & QL-HL & AR(1) & Std(e)/Std(C) \\
\hline Empirical values & 2.8 & 0.42 & 1.51 & 0.79 & 4.97 \\
FL and CPS & 1.5 & 0 & 1.75 & 0.67 & 4.94 \\
FL and LRS & 1.5 & 0 & 1.75 & 0.67 & 4.62 \\
FL and UIPS & 1.5 & 0 & 1.75 & 0.67 & 51.5 \\
FL and MPS & 1.5 & 0 & 1.75 & 0.67 & 4.62 \\
SL and CPS & 1.75 & 0 & 1.75 & 0.7 & 4.97 \\
SL and LRS & 2.75 & 0.27 & 1.75 & 0.69 & 4.64 \\
SL and UIPS & 1.75 & 0 & 1.5 & 0.89 & 41.8 \\
SL and MPS & 2.75 & 0.27 & 1.75 & 4.64 \\
\hline
\end{tabular}

HL expresses half-life (measured in years), UL/HL expresses up-life over half-life, QL-HL expresses quarter-life minus half-life, AR(1) expresses the first-order autocorrelation of the HP-filtered series, and $\operatorname{Std}(\mathrm{e}) / \operatorname{Std}(\mathrm{C})$ expresses the standard deviation of HP-filtered e (real exchange rate) divided by the standard deviation of HP-filtered C (consumption). The point estimates for AR(1) and Std(e)/ $\operatorname{Std}(C)$ are calculated by simulating 1000 data series from each model, in which each data length is 127 , and the point estimate is the median value of the resulting distribution exactly following Steinsson (2008). FL and SL mean flexible and staggered loan contracts, respectively. CPS, LRS, UIPS, and MPS denote cost-push shock, loan rate shock, UIP shock, and monetary policy shock, respectively.

The reason for this is in line with that given by Steinsson (2008). By setting the home bias parameter very high, the home cost-push shock has only negligible effects on foreign variables. Under such circumstances, the hump-shaped responses of real exchange rates come from the responses in home consumption as implied by Equation (23). Therefore, eventually, it depends on the dynamics of real interest rates in the home country since the consumption can be represented as the discounted sum of future real interest rates according to the Euler conditions given by Equation (19). Here, after a cost-push shock hits the economy, inflation and consumption can move in opposite directions while they co-move to the monetary policy shocks. As a result, real interest rates affected naturally by short-term nominal interest rates set through the Taylor (1993) - type rule show non-monotonic responses. ${ }^{13}$ Therefore, we can reproduce the hump-shaped responses in real interest rates and therefore in real exchange rates to cost-push shocks. A loan rate shock itself is not a cost-push shock, but is considered to be a more micro-founded cost-push shock. Thus, a direct shock to loan interest rates works as if it were a cost-push shock and therefore results in hump-shaped responses in the real exchange rate.

At the same time, due to this very reason, a model with the infrequent price change cannot produce the hump-shaped real exchange rate dynamics for monetary policy shock. The effects of the monetary policy shock through real interest rates completely dominate those through loan rates under the flexible price setting. By the same reason in the previous section, the real exchange rate dynamics are solely determined by the UIP shock that follows the AR(1) process.

\subsection{Welfare cost}

We compute the welfare cost of adding staggered price or loan contracts to the flexible price and loan model. Following Schmitt-Grohé and Uribe (2007), we first define the welfare under the flexible price and loan equilibrium $V_{0}^{f}$ as

$$
\begin{aligned}
V_{0}^{f} & \equiv E_{0} \sum_{t=0}^{\infty} \beta^{t}\left[u\left(C_{t}^{f}\right)-v\left(l_{h, t}^{f}\right)-v\left(l_{\bar{h}, t}^{f}\right)\right] \\
& \equiv E_{0} \sum_{t=0}^{\infty} \beta^{t} u\left(C_{t}^{f}\right)-E_{0} \sum_{t=0}^{\infty} \beta^{t}\left[v\left(l_{h, t}^{f}\right)+v\left(l_{\bar{h}, t}^{f}\right)\right] \\
& \equiv V_{C, 0}^{f}-V_{l, 0}^{f} .
\end{aligned}
$$

and that under alternative models $V_{0}^{a}$ as

13 This logic is similar to G. Benigno (2004). 
Table 4

Properties of real exchange rate under sticky price.

\begin{tabular}{lllllc}
\hline Setting & HL & UL/HL & QL-HL & AR(1) & Std $(e) / \operatorname{Std}(C)$ \\
\hline Empirical values & 2.8 & 0.42 & 1.51 & 0.79 & 4.97 \\
FL and CPS & 2.75 & 0.18 & 1.75 & 0.84 & 4.96 \\
FL and LRS & 2.75 & 0.18 & 1.75 & 0.84 & 4.64 \\
FL and UIPS & 1.25 & 0 & 1.75 & 0.66 & 99.9 \\
FL and MPS & 0.25 & 0 & 0.75 & 0.52 & 5.02 \\
SL and CPS & 2.75 & 0.25 & 1.75 & 0.84 & 4.97 \\
SL and LRS & 3.25 & 0.31 & 1.75 & 0.86 & 4.64 \\
SL and UIPS & 1.25 & 0 & 1.75 & 0.66 & 91.2 \\
SL and MPS & 0.25 & 0 & 0.75 & 0.52 & 5.02 \\
\hline
\end{tabular}

HL expresses half-life (measured in years), UL/HL expresses up-life over half-life, QL-HL expresses quarter-life minus half-life, AR(1) expresses the first-order autocorrelation of the HP-filtered series, and $\operatorname{Std}(\mathrm{e}) / \operatorname{Std}(\mathrm{C})$ expresses the standard deviation of HP-filtered e (real exchange rate) divided by the standard deviation of HP-filtered C (consumption). The point estimates for AR(1) and Std(e)/ $\operatorname{Std}(C)$ are calculated by simulating 1000 data series from each model, in which each data length is 127 , and the point estimate is the median value of the resulting distribution exactly following Steinsson (2008). FL and SL mean flexible and staggered loan contracts, respectively. CPS, LRS, UIPS, and MPS denote cost-push shock, loan rate shock, UIP shock, and monetary policy shock, respectively.

$$
\begin{aligned}
V_{0}^{a} & \equiv E_{0} \sum_{t=0}^{\infty} \beta^{t}\left[u\left(C_{t}^{a}\right)-v\left(l_{h, t}^{a}\right)-v\left(l_{\bar{h}, t}^{a}\right)\right] \\
& \equiv E_{0} \sum_{t=0}^{\infty} \beta^{t} u\left(C_{t}^{a}\right)-E_{0} \sum_{t=0}^{\infty} \beta^{t}\left[v\left(l_{h, t}^{a}\right)+v\left(l_{\bar{h}, t}^{a}\right)\right] \\
& \equiv V_{C, 0}^{a}-V_{l, 0}^{a} .
\end{aligned}
$$

Superscript $f$ denotes the variables under flexible price and loan contracts while superscript $a$ denotes those under alternative models. Alternative model here is either the model only with price rigidities or that only with loan rate rigidities. We compute the welfare cost in consumption unit $\lambda_{c}$ as in

$$
\begin{gathered}
V_{0}^{a}=E_{0} \sum_{t=0}^{\infty} \beta^{t}\left[u\left(\left(1-\lambda_{c}\right) C_{t}^{f}\right)-v\left(f_{h, t}^{f}\right)-v\left(l_{\bar{h}, t}^{f}\right)\right] \\
=E_{0} \sum_{t=0}^{\infty} \beta^{t} u\left(\left(1-\lambda_{c}\right) C_{t}^{f}\right)-V_{l, 0}^{f} .
\end{gathered}
$$

Since we assume

$$
\begin{gathered}
u\left(C_{t}\right)=\frac{C_{t}^{1-v}}{1-v}, \\
V_{0}^{a}=E_{0} \sum_{t=0}^{\infty} \beta^{t} u\left(\left(1-\lambda_{c}\right) C_{t}^{f}\right)-V_{l, 0}^{f} \\
=\left(1-\lambda_{c}\right)^{1-v} V_{C, 0}^{f}-V_{l, 0}^{f} .
\end{gathered}
$$

Hence, the welfare cost in consumption unit is computed as

$$
\lambda_{c}=1-\left(\frac{V_{0}^{a}+V_{l, 0}^{f}}{V_{C, 0}^{f}}\right)^{\frac{1}{1-v}}
$$

We compute $V_{0}, V_{C, 0}$ and $V_{l, 0}$ by simulating the 2nd-order-approximated model.

When we examine the technology shock, we use the process estimated by Schmitt-Grohé and Uribe (2007):

$$
z_{t}=0.8556_{t-1}+u_{z, t}, u_{z, t} \sim N\left(0,0.0064^{2}\right),
$$

while for the loan rate shock, we calibrate the stochastic process as 


$$
m_{t}=0.9 m_{t-1}+u_{m, t}, u_{m, t} \sim N\left(0,0.01^{2}\right) .
$$

For the empirically estimated technology shock by Schmitt-Grohé and Uribe (2007), the welfare cost in consumption unit for incorporating the staggered loan contracts is very small under our benchmark calibration shown in Table $2 .{ }^{14}$ It is equivalent to the permanent loss of consumption in $0.0004 \%$. On the other hand, the welfare loss from only incorporating staggered price contracts is $0.01 \%$. For the loan rate shock, it becomes $0.02 \%$ for only having staggered loan and $0.04 \%$ for only having staggered price contracts. The technology shock directly affects the real marginal cost for pricing while the loan rate shock immediately alters the nominal marginal cost for making loans. This makes the welfare cost in incorporating the staggered loan contracts relatively larger in the case when the loan rate shock hits the economy.

\section{Concluding remarks}

Empirical papers have shown the nontrivial roles of financial market imperfections, which can be represented as a staggered loan contract. We introduce this into an otherwise standard NOEM model in a tractable manner. Simulation results with such staggered loan contracts can generate persistent, volatile, and hump-shaped responses in real exchange rates for both supply and demand shocks, such as cost-push, loan rate, and monetary policy shocks. In particular, the fact that we can reproduce such a realistic response via a monetary policy shock merits attention, because reproduction has been considered very difficult by previous studies. According to the results in this paper, financial market imperfections are very important elements in understanding the realistic real exchange rate dynamics.

\section{Acknowledgments}

We thank an anonymous referee, Guillermo Calvo, Marc Giannoni, Federico Mandelman, Alex Mikov, Paul McNelis, Bruce Preston, Jón Steinsson, and seminar participants at Columbia University and the Bank of Japan for beneficial discussions, and especially Giancalro Corsetti and Mike Woodford for insightful comments, suggestions, and encouragements. We receive a significant technical support from Jouchi Nakajima. The views expressed in this paper are those of the authors and do not necessarily reflect the official views of the Bank of Japan.

\section{Appendix}

A Derivation of the model

\section{A.1 Equilibrium conditions}

A.1.1 Household. Domestic. From household's utility maximization in Equations (1)-(6), we can derive

$$
\begin{aligned}
& u^{\prime}\left(C_{t}\right)=\beta\left(1+i_{t}\right) E_{t}\left[u^{\prime}\left(C_{t+1}\right) \frac{P_{t}}{P_{t+1}}\right] \\
& \frac{u^{\prime}\left(C_{t}\right)}{u^{\prime}\left(C_{t+1}\right)}=\frac{\beta P_{t}}{X_{t, t+1} P_{t+1}}
\end{aligned}
$$

\footnotetext{
14 This reflects the assumption about the labor union, which is necessary in obtaining the nonlinear equilibrium conditions as shown by Schmitt-Grohé and Uribe (2006) and Schmitt-Grohé and Uribe (2007), to some extent.
} 


$$
\frac{w_{t}(h)}{P_{t}}=w_{h, t}=\frac{\epsilon}{\epsilon-1} \frac{v^{\prime}\left(l_{h, t}\right)}{u^{\prime}\left(C_{t}\right)}
$$

and

$$
\frac{w_{t}(\bar{h})}{P_{t}}=w_{\bar{h}, t}=\frac{\epsilon}{\epsilon-1} \frac{v^{\prime}\left(l_{\bar{h}, t}\right)}{u^{\prime}\left(C_{t}\right)} .
$$

Note that thanks to the assumptions about a large representative family and no wage rigidities, wages can be expressed only with aggregate variables for the representative household. There, however, exists wage heterogeneity between different groups.

From the intra-temporal cost minimization problem on Equations (7)-(9),

$$
\begin{aligned}
& P_{t} \equiv P_{H, t}^{\phi} P_{F, t}^{1-\phi}, \\
& c_{t}(f)=\left[\frac{p_{t}(f)}{P_{H, t}}\right]^{-\sigma} C_{H, t}=\phi\left[\frac{p_{t}(f)}{P_{H, t}}\right]^{-\sigma}\left(\frac{P_{H, t}}{P_{t}}\right)^{-1} C_{t},
\end{aligned}
$$

and

$$
c_{t}\left(f^{*}\right)=\left[\frac{p_{t}\left(f^{*}\right)}{P_{F, t}}\right]^{-\sigma} C_{F, t}=(1-\phi)\left[\frac{p_{t}\left(f^{*}\right)}{P_{F, t}}\right]^{-\sigma}\left(\frac{P_{F, t}}{P_{t}}\right)^{-1} C_{t}
$$

where we define

$$
\begin{aligned}
& P_{H, t} \equiv\left[\int_{0}^{1} p_{t}(f)^{1-\sigma} d f\right]^{\frac{1}{1-\sigma},} \\
& P_{F, t} \equiv\left[\int_{0}^{1} p_{t}\left(f^{*}\right)^{1-\sigma} d f^{*}\right]^{\frac{1}{1-\sigma}},
\end{aligned}
$$

and $p_{t}(f)$ is the price on $c_{t}(f)$, and $p_{t}\left(f^{*}\right)$ is the price on $c_{t}\left(f^{*}\right)$.

Foreign. Similarly, from the optimization problem in the foreign country, we can derive

$$
\begin{aligned}
& u^{\prime}\left(C_{t}^{*}\right)=\beta\left(1+i_{t}^{*}\right) \mathrm{E}_{t}\left[u^{\prime}\left(C_{t+1}^{*}\right) \frac{P_{t}^{*}}{P_{t+1}^{*}}\right], \\
& \frac{u^{\prime}\left(C_{t}^{*}\right)}{u^{\prime}\left(C_{t+1}^{*}\right)}=\beta \frac{S_{t}}{S_{t+1} X_{t, t+1}} \frac{P_{t}^{*}}{P_{t+1}^{*}}, \\
& \frac{w_{t}\left(h^{*}\right)}{P_{t}^{*}}=w_{h^{*}, t}=\frac{\epsilon}{\epsilon-1} \frac{v^{\prime} l_{h^{*}, t}}{u^{\prime}\left(C_{t}^{*}\right)}, \\
& \frac{w_{t}\left(\bar{h}^{*}\right)}{P_{t}^{*}}=w_{\bar{h}^{*}, t}=\frac{\epsilon}{\epsilon-1} \frac{v^{\prime}\left(l_{\vec{h}^{*}, t}\right)}{u^{\prime}\left(C_{t}^{*}\right)}, \\
& P_{t}^{*} \equiv\left(P_{H, t}^{*}\right)^{1-\phi}\left(P_{F, t}^{*}\right)^{\phi}, \\
& c_{t}^{*}(f)=\left[\frac{p_{t}^{*}(f)}{P_{H, t}^{*}}\right]^{-\sigma} C_{H, t}^{*}=(1-\phi)\left[\frac{p_{t}^{*}(f)}{P_{H, t}^{*}}\right]^{-\sigma}\left(\frac{P_{H, t}^{*}}{P_{t}^{*}}\right)^{-1} C_{t}^{*},
\end{aligned}
$$


and

$$
c_{t}^{*}\left(f^{*}\right)=\left[\frac{p_{t}^{*}\left(f^{*}\right)}{P_{F, t}^{*}}\right]^{-\sigma} C_{F, t}^{*}=\phi\left[\frac{p_{t}^{*}\left(f^{*}\right)}{P_{F, t}^{*}}\right]^{-\sigma}\left(\frac{P_{F, t}^{*}}{P_{t}^{*}}\right)^{-1} C_{t}^{*},
$$

International Financial Transactions From the inter-temporal optimality conditions in Equations (34) and (42), we can obtain the condition for international complete financial market:

$$
e_{t}=\frac{S_{t} P_{t}^{*}}{P_{t}}=\frac{u^{\prime}\left(C_{t}^{*}\right)}{u^{\prime}\left(C_{t}\right)} \exp \left(x_{t}\right)
$$

where $e_{t}$ is the real exchange rate. Similarly, we can also derive the uncovered interest rate parity condition:

$$
\frac{S_{t+1}}{S_{t}}\left(1+i_{t}^{*}\right)=1+i_{t}
$$

A.1.2 Firms. Domestic From the cost minimization problem on the labor bundles in Equations (11)-(14), we can derive

$$
l_{t}(h, f)=\frac{1}{n}\left[\frac{R_{t}(h) w_{t}(h)}{\Omega_{h, t}}\right]^{-\epsilon} L_{h, t}(f)=\left[\frac{R_{t}(h) w_{t}(h)}{\Omega_{h, t}}\right]^{-\epsilon}\left(\frac{\Omega_{h, t}}{\Omega_{t}}\right)^{-1} L_{t}(f),
$$

and

$$
l_{t}(\bar{h}, f)=\frac{1}{1-n}\left[\frac{R_{t}(\bar{h}) w_{t}(\bar{h})}{\Omega_{\bar{h}, t}}\right]^{-\epsilon} L_{\bar{h}, t}(f)=\left[\frac{R_{t}(\bar{h}) w_{t}(\bar{h})}{\Omega_{\bar{h}, t}}\right]^{-\epsilon}\left(\frac{\Omega_{\bar{h}, t}}{\Omega_{t}}\right)^{-1} L_{t}(f),
$$

where

$$
\begin{aligned}
& \Omega_{t} \equiv \Omega_{h, t}^{n} \Omega_{\bar{h}, t}^{1-n}, \\
& \Omega_{h, t} \equiv\left\{\frac{1}{n} \int_{0}^{n}\left[R_{t}(h) w_{t}(h)\right]^{1-\epsilon} d h\right\}^{\frac{1}{1-\epsilon}},
\end{aligned}
$$

and

$$
\Omega_{\bar{h}, t} \equiv\left\{\frac{1}{1-n} \int_{0}^{1}\left[R_{t}(\bar{h}) w_{t}(\bar{h})\right]^{1-\epsilon} d \bar{h}\right\}^{\frac{1}{1-\epsilon}} .
$$

By substituting (35) and (36), ${ }^{15}$ we can derive

$$
\Omega_{h, t} \equiv w_{h, t} P_{t}\left[\frac{1}{n} \int_{0}^{n} R_{t}(h)^{1-\epsilon} d h\right]^{\frac{1}{1-\epsilon}}=w_{h, t} P_{t} R_{h, t},
$$

\footnotetext{
${ }^{15}$ We implicitly assume that banks cannot access to the information on the wages offered by the union. This enables us to obtain the nonlinear system of equations. Another approach is to define the aggregate loan rate index as $R_{H, t}=\left[\frac{1}{n} \int_{0}^{n} R_{t}(h)^{1-\epsilon} \mathrm{d} h\right]^{\frac{1}{1-\epsilon}}$. These are innocuous as long as the model is solved with the first-order approximation.
} 


$$
\Omega_{\bar{h}, t} \equiv w_{\bar{h}, t} P_{t}\left[\frac{1}{1-n} \int_{n}^{1} R_{t}(\bar{h})^{1-\epsilon} d \bar{h}\right]^{\frac{1}{1-\epsilon}}=w_{\bar{h}, t} P_{t} R_{\bar{h}, t},
$$

and

$$
\Omega_{t} \equiv P_{t} w_{h, t}^{n} w_{\bar{h}, t}^{1-n} R_{h, t}^{n}\left(R_{\bar{h}, t}\right)^{1-n}=P_{t} w_{h, t}^{n} w_{\bar{h}, t}^{1-n} R_{t} .
$$

Thus, above conditions are now rewritten as

$$
\begin{aligned}
& l_{t}(h)=\frac{1}{n}\left[\frac{R_{t}(h)}{R_{h, t}}\right]^{-\epsilon} L_{h, t}=\left[\frac{R_{t}(h)}{R_{h, t}}\right]^{-\epsilon}\left(\frac{w_{h, t} R_{h, t}}{w_{h, t}^{n} w_{\bar{h}, t}^{1-n} R_{t}}\right)^{-1} L_{t}, \\
& l_{t}(\bar{h})=\frac{1}{1-n}\left[\frac{R_{t}(\bar{h})}{R_{\bar{h}, t}}\right]^{-\epsilon} L_{\bar{h}, t}=\left[\frac{R_{t}(\bar{h})}{R_{\bar{h}, t}}\right]^{-\epsilon}\left(\frac{w_{\bar{h}, t} R_{\bar{h}, t}}{w_{h, t}^{n} w_{\bar{h}, t}^{1-n} R_{t}}\right)^{-1} L_{t},
\end{aligned}
$$

where we also eliminate the index $f$ under the assumption of symmetric equilibrium.

Accordingly, amounts of loan borrowed by firm $f$ to the labor types $h$ and $\bar{h}$, namely $q_{t}(h)$ and $q_{t}(\bar{h})$ are defined as follows:

$$
q_{t}(h)=\bar{\gamma} w_{t}(h) l_{t}(h)=\bar{\gamma} w_{h, t}\left[\frac{R_{t}(h)}{R_{h, t}}\right]^{-\epsilon}\left(\frac{w_{h, t} R_{h, t}}{w_{h, t}^{n} w_{\bar{h}, t}^{1-n} R_{t}}\right)^{-1} L_{t},
$$

and

$$
q_{t}(\bar{h})=\bar{\gamma} w_{t}(\bar{h}) l_{t}(\bar{h})=\bar{\gamma} w_{\bar{h}, t}\left[\frac{R_{t}(\bar{h})}{R_{\bar{h}, t}}\right]^{-\epsilon}\left(\frac{w_{\bar{h}, t} R_{\bar{h}, t}}{w_{h, t}^{n} w_{\bar{h}, t}^{1-n} R_{t}}\right)^{-1} L_{t} .
$$

The optimal price on the domestic sales set by the domestic firm $\tilde{p}_{t}$ in Equation (15) is given by

$$
E_{t} \sum_{T=t}^{\infty}(\alpha \beta)^{T-t} u^{\prime}\left(C_{T}\right) C_{t}\left(\frac{1}{P_{H, T}}\right)^{-\sigma}\left[\frac{\tilde{P}_{t}}{P_{H, t}} \frac{P_{H, t}}{P_{H, T}}-\frac{\sigma}{\sigma-1} \frac{w_{h, T}^{n} w_{\bar{h}, T}^{1-n} P_{T} R_{T}}{\exp \left(z_{t}\right) P_{H, T}}\right]=0,
$$

where we use Equations (35), (39), (40), and (52). Each firm resets its price $\tilde{p}_{t}$ with probability $(1-\alpha)$. Under this setting, the price dispersion term which will be defined later in Equation (97) is expressed as

$$
\begin{gathered}
\Delta_{H, t}=(1-\alpha)\left(\frac{\tilde{P}_{t}}{P_{H, t}}\right)^{-\sigma}+\alpha \int_{0}^{1}\left[\frac{p_{t-1}(f)}{P_{H, t}}\right]^{-\sigma} d f \\
=(1-\alpha)\left(\frac{\tilde{P}_{t}}{P_{H, t}}\right)^{-\sigma}+\alpha\left(\frac{P_{H, t}}{P_{H, t-1}}\right)^{\sigma} \Delta_{H, t-1} .
\end{gathered}
$$

On the other hand, from Equation (41), we can derive

$$
\frac{\tilde{P}_{t}}{P_{H, t}}=\left[\frac{1-\alpha\left(\frac{P_{H, t}}{P_{H, t-1}}\right)^{\sigma-1}}{1-\alpha}\right]^{\frac{1}{1-\sigma}} .
$$

Consequently, by combining above two equations together, we now have 


$$
\Delta_{H, t}=(1-\alpha)\left[\frac{1-\alpha\left(\frac{P_{H, t}}{P_{H, t-1}}\right)^{\sigma-1}}{1-\alpha}\right]^{\frac{\sigma}{\sigma-1}}+\alpha\left(\frac{P_{H, t}}{P_{H, t-1}}\right)^{\sigma} \Delta_{H, t-1} .
$$

We re-write Equation (54) as

$$
\left[\frac{1-\alpha\left(\frac{P_{H, t}}{P_{H, t-1}}\right)^{\sigma-1}}{1-\alpha}\right]^{\frac{1}{1-\sigma}} F_{H, t}^{P}=K_{H, t}^{P},
$$

where we substitute Equation (56) and define

$$
F_{H, t}^{P} \equiv E_{t} \sum_{T=t}^{\infty}(\alpha \beta)^{T-t} \frac{u^{\prime}\left(C_{T}\right) C_{T}}{u^{\partial \prime}\left(C_{t}\right) C_{t}}\left(\frac{P_{H, t}}{P_{H, T}}\right)^{1-\sigma}=1+E_{t} \alpha \beta \frac{u^{\prime}\left(C_{t+1}\right) C_{t+1}}{u^{\prime}\left(C_{t}\right) C_{t}}\left(\frac{P_{H, t}}{P_{H, t+1}}\right)^{1-\sigma} F_{H, t+1}^{P},
$$

and

$$
\begin{gathered}
K_{H, t}^{P} \equiv E_{t} \sum_{T=t}^{\infty}(\alpha \beta)^{T-t} \frac{u^{\prime}\left(C_{T}\right) C_{T}}{u^{\prime}\left(C_{t}\right) C_{t}}\left(\frac{P_{H, t}}{P_{H, T}}\right)^{-\sigma} \frac{\sigma}{\sigma-1} \frac{w_{h, t}^{n} w_{\bar{h}, t}^{1-n} P_{t} R_{t}}{\exp \left(z_{t}\right) P_{H, t}} \\
=\frac{\sigma}{\sigma-1} \frac{\exp \left(a_{t}\right) w_{h, t}^{n} w_{\bar{h}, t}^{1-n} P_{t} R_{t}}{\exp \left(z_{t}\right) P_{H, t}}+E_{t} \alpha \beta \frac{u^{\prime}\left(C_{t+1}\right) C_{t+1}}{u^{\prime}\left(C_{t}\right) C_{t}}\left(\frac{P_{H, t}}{P_{H, t+1}}\right)^{-\sigma} K_{H, t+1}^{P} .
\end{gathered}
$$

Similarly, from the optimal price on the foreign sales set by domestic firms $\tilde{p}_{t}^{*}$, we can derive

$$
\left[\frac{1-\alpha\left(\frac{P_{H, t}^{*}}{P_{H, t-1}^{*}}\right)^{\sigma-1}}{1-\alpha}\right]^{\frac{1}{1-\sigma}} F_{H, t}^{P^{*}}=K_{H, t}^{P^{*}},
$$

with

$$
\begin{aligned}
& F_{H, t}^{P_{*}^{*}}=1+E_{t} \alpha \beta \frac{u^{\prime}\left(C_{t+1}\right) C_{t+1}^{*} P_{t} P_{t+1}^{*}}{u^{\prime}\left(C_{t}\right) C_{t}^{*} P_{t+1} P_{t}^{*}}\left(\frac{P_{H, t}^{*}}{P_{H, t+1}^{*}}\right)^{1-\sigma} F_{H, t+1}^{P^{*}}, \\
& K_{H, t}^{P^{*}}=\frac{\sigma}{\sigma-1} \frac{w_{h, t}^{n} w_{\bar{h}, t}^{1-n} P_{t} R_{t}}{\exp \left(z_{t}\right) S_{t} P_{H, t}^{*}}+E_{t} \alpha \beta \frac{u^{\prime}\left(C_{t+1}\right) C_{t+1}^{*} P_{t} P_{t+1}^{*}}{u^{\prime}\left(C_{t}\right) C_{t}^{*} P_{t+1} P_{t}^{*}}\left(\frac{P_{H, t}^{*}}{P_{H, t+1}^{*}}\right)^{-\sigma} K_{H, t+1}^{P^{*}},
\end{aligned}
$$

and

$$
\Delta_{H, t}^{*}=(1-\alpha)\left[\frac{1-\alpha\left(\frac{P_{H, t}^{*}}{P_{H, t-1}^{*}}\right)^{\sigma-1}}{1-\alpha}\right]^{\frac{\sigma}{\sigma-1}}+\alpha\left(\frac{P_{H, t}^{*}}{P_{H, t-1}^{*}}\right)^{\sigma} \Delta_{H, t-1}^{*} .
$$


Foreign From the cost minimization problem in the foreign country, we have

$$
\begin{aligned}
& \Omega_{h^{*}, t} \equiv w_{h^{*}, t} P_{t}^{*}\left[\frac{1}{1-n} \int_{0}^{n} R_{t}\left(h^{*}\right)^{1-\epsilon} d h\right]^{\frac{1}{1-\epsilon}}=w_{h^{*}, t} P_{t}^{*} R_{h^{*}, t}, \\
& \Omega_{\bar{h}^{*}, t} \equiv w_{\bar{h}^{*}, t} P_{t}^{*}\left[\frac{1}{n} \int_{n}^{1} R_{t}\left(\bar{h}^{*}\right)^{1-\epsilon} d \bar{h}\right]^{\frac{1}{1-\epsilon}}=w_{\bar{h}^{*}, t} P_{t}^{*} R_{\bar{h}^{*}, t}, \\
& \Omega_{t}^{*} \equiv P_{t}^{*} w_{h^{*}, t}^{1-n} w_{\bar{h}^{*}, t}^{n} R_{h^{*}, t}^{1-n} R_{\bar{h}^{*}, t}^{n}=P_{t}^{*} w_{h^{*}, t}^{1-n} w_{\bar{h}^{*}, t}^{n} R_{t}^{*} \\
& l_{t}\left(h^{*}\right)=\frac{1}{n}\left[\frac{R_{t}\left(h^{*}\right)}{R_{h^{*}, t}}\right]^{-\epsilon} L_{h^{*}, t}=\left[\frac{R_{t}\left(h^{*}\right)}{R_{h^{*}, t}}\right]^{-\epsilon}\left(\frac{w_{h^{*}, t} R_{h^{*}, t}}{w_{h^{*}, t}^{1-n} w_{\bar{h}^{*}, t}^{n} R_{t}^{*}}\right)^{-1} L_{t}^{*}, \\
& l_{t}\left(\bar{h}^{*}\right)=\frac{1}{1-n}\left[\frac{R_{t}\left(\bar{h}^{*}\right)}{R_{\bar{h}^{*}, t}}\right]^{-\epsilon} L_{\bar{h}^{*}, t}=\left[\frac{R_{t}\left(\bar{h}^{*}\right)}{R_{\bar{h}^{*}, t}}\right]^{-\epsilon}\left(\frac{w_{\bar{h}^{*}, t} R_{\bar{h}^{*}, t}}{w_{h^{*}, t}^{1-n} w_{\bar{h}^{*}, t}^{n} R_{t}^{*}}\right)^{-1} L_{t}^{*}, \\
& q_{t}\left(h^{*}\right)=\bar{\gamma} w_{t}\left(h^{*}\right) l_{t}\left(h^{*}\right)=\bar{\gamma} w_{h^{*}, t}\left[\frac{R_{t}\left(h^{*}\right)}{R_{h^{*}, t}}\right]^{-\epsilon}\left(\frac{w_{h^{*}, t} R_{h^{*}, t}}{w_{h^{*}, t}^{1-n} w_{\bar{h}^{*}, t}^{n} R_{t}^{*}}\right)^{-1} L_{t}^{*},
\end{aligned}
$$

and

$$
q_{t}\left(\bar{h}^{*}\right)=\bar{\gamma} w_{t}\left(\bar{h}^{*}\right) l_{t}\left(\bar{h}^{*}\right)=\bar{\gamma} w_{\bar{h}^{*}, t}\left[\frac{R_{t}\left(\bar{h}^{*}\right)}{R_{\bar{h}^{*}, t}}\right]^{-\epsilon}\left(\frac{w_{\bar{h}^{*}, t} R_{\bar{h}^{*}, t}}{w_{h^{*}, t}^{1-n} w_{\bar{h}^{*}, t}^{n} R_{t}}\right)^{-1} L_{t}^{*} .
$$

From the optimal price settings by foreign firms, we obtain

$$
\begin{aligned}
\Delta_{F, t}^{*}=(1-\alpha)\left[\frac{1-\alpha\left(\frac{P_{F, t}^{*}}{P_{F, t-1}^{*}}\right)^{\sigma-1}}{1-\alpha}\right]^{\frac{\sigma}{\sigma-1}}+\alpha\left(\frac{P_{F, t}^{*}}{P_{F, t-1}^{*}}\right)^{\sigma} \Delta_{F, t-1}^{*}, & {\left[\frac{1-\alpha\left(\frac{P_{F, t}^{*}}{P_{F, t-1}^{*}}\right)^{\sigma-1}}{1-\alpha}\right]^{\frac{1}{1-\sigma} F_{F, t}^{P^{*}}=K_{F, t}^{P^{*}},} } \\
& {\left[\frac{u^{\prime}\left(C_{t+1}^{*}\right) C_{t+1}^{*}}{u^{\prime}\left(C_{t}^{*}\right) C_{t}^{*}}\left(\frac{P_{F, t}^{*}}{P_{F, t+1}^{*}}\right)^{1-\sigma} F_{F, t+1}^{P^{*}},\right.}
\end{aligned}
$$




$$
K_{F, t}^{P^{*}}=\frac{\sigma}{\sigma-1} \frac{w_{h^{*}, t}^{1-n} w_{\bar{h}^{*}, t}^{n} P_{t}^{*} R_{t}^{*}}{P_{F, t}^{*}}+E_{t} \alpha \beta \frac{u^{\prime}\left(C_{t+1}^{*}\right) C_{t+1}^{*}}{u^{\prime}\left(C_{t}^{*}\right) C_{t}^{*}}\left(\frac{P_{F, t}^{*}}{P_{F, t+1}^{*}}\right)^{-\sigma} K_{F, t+1}^{P^{*}},
$$

$$
\begin{aligned}
& {\left[\frac{1-\alpha\left(\frac{P_{F, t}}{P_{F, t-1}}\right)^{\sigma-1}}{1-\alpha}\right]^{\frac{1}{1-\sigma}} F_{F, t}^{P}=K_{F, t}^{P},} \\
& F_{F, t}^{P}=1+E_{t} \alpha \beta \frac{u^{\prime}\left(C_{t+1}^{*}\right) C_{t+1} P_{t+1} P_{t}^{*}}{u^{\prime}\left(C_{t}^{*}\right) C_{t} P_{t} P_{t+1}^{*}}\left(\frac{P_{F, t}}{P_{F, t+1}}\right)^{1-\sigma} F_{F, t+1}^{P},
\end{aligned}
$$

$$
K_{F, t}^{P}=\frac{\sigma}{\sigma-1} \frac{S_{t} w_{h^{*}, t}^{1-n} w_{\bar{h}^{*}, t}^{n} P_{t}^{*} R_{t}^{*}}{P_{F, t}}+E_{t} \alpha \beta \frac{u^{\prime}\left(C_{t+1}^{*}\right) C_{t+1} P_{t+1} P_{t}^{*}}{u^{\prime}\left(C_{t}^{*}\right) C_{t} P_{t} P_{t+1}^{*}}\left(\frac{P_{F, t}}{P_{F, t+1}}\right)^{-\sigma} K_{F, t+1}^{P},
$$

and

$$
\Delta_{F, t}=(1-\alpha)\left[\frac{1-\alpha\left(\frac{P_{F, t}}{P_{F, t-1}}\right)^{\sigma-1}}{1-\alpha}\right]^{\frac{\sigma}{\sigma-1}}+\alpha\left(\frac{P_{F, t}}{P_{F, t-1}}\right)^{\sigma} \Delta_{F, t-1} .
$$

\section{A.2 Banks} as

Domestic The optimal loan rate $\tilde{R}_{\bar{h}^{*}, t}$ under symmetric equilibrium derived from Equation (16) is set

$$
\begin{aligned}
& E_{t} \sum_{T=t}^{\infty}(\psi \beta)^{T-t} \frac{u^{\prime}\left(C_{T}\right) P_{t} w_{\vec{h}^{*}, T} L_{T}^{*}}{u^{\prime}\left(C_{t}\right) P_{T}}\left(\frac{w_{h^{*}, T} R_{h^{*}, T}}{w_{\vec{h}^{*}, T} R_{\vec{h}^{*}, T}}\right)^{1-n}\left(\frac{1}{R_{\vec{h}^{*}, T}}\right)^{-\epsilon-1} \\
& \times\left[\frac{\tilde{R}_{\vec{h}^{*}, t}}{R_{\vec{h}^{*}, t}} \frac{R_{\vec{h}^{*}, t}}{R_{\vec{h}^{*}, T}}-\frac{\epsilon}{\epsilon-1} \frac{S_{T}\left(1+i_{T}\right)}{S_{T+1} R_{\vec{h}^{*}, T}}\right]=0
\end{aligned}
$$

where we use Equations (34) and (68). Because the international private banks that have the opportunity to reset their loan interest rates will set the same loan interest rate, from Equation (64), we can derive

$$
\frac{\tilde{R}_{\vec{h}^{*}, t}}{R_{\vec{h}^{*}, t}}=\left[\frac{1-\psi\left(\frac{R_{\vec{h}^{*}, t}}{R_{\vec{h}^{*}, t-1}}\right)^{\epsilon-1}}{1-\psi}\right]^{\frac{1}{1-\epsilon}},
$$

Substituting Equation (79) into (78) results in 


$$
\left[\frac{1-\psi\left(\frac{R_{\bar{h}^{*}, t}}{R_{\bar{h}^{*}, t-1}}\right)^{\epsilon-1}}{1-\psi}\right]^{\frac{1}{1-\epsilon}} F_{\vec{h}^{*}, t}^{R}=K_{\bar{h}^{*}, t}^{R},
$$

where

$$
\begin{aligned}
& F_{\bar{h}^{*}, t}^{R}=E_{t} \sum_{T=t}^{\infty}(\psi \beta)^{T-t} \frac{u^{\prime}\left(C_{T}\right) P_{t} w_{\bar{h}^{*}, T} L_{T}^{*}}{u^{\prime}\left(C_{t}\right) P_{T} w_{\bar{h}^{*}, t} L_{t}^{*}}\left(\frac{w_{h^{*}, T} w_{\bar{h}^{*}, t} R_{h^{*}, T} R_{\bar{h}^{*}, t}}{w_{h^{*}, t} w_{\bar{h}^{*}, T} R_{h^{*}, t} R_{\bar{h}^{*}, T}}\right)^{1-n}\left(\frac{R_{\bar{h}^{*}, t}}{R_{\bar{h}^{*}, T}}\right)^{-\epsilon} \\
& =1+E_{t} \psi \beta \frac{u^{\prime}\left(C_{t+1}\right) P_{t} w_{\vec{h}^{*}, t+1} L_{t+1}^{*}}{u^{\prime}\left(C_{t}\right) P_{t+1} w_{\vec{h}^{*}, t} L_{t}^{*}}\left(\frac{w_{h^{*}, t+1} w_{\bar{h}^{*}, t} R_{h^{*}, t+1} R_{\vec{h}^{*}, t}}{w_{h^{*}, t} w_{\vec{h}^{*}, t+1} R_{h^{*}, t} R_{\bar{h}^{*}, t+1}}\right)^{1-n}\left(\frac{R_{\bar{h}^{*}, t}}{R_{\vec{h}^{*}, t+1}}\right)^{-\epsilon} F_{\bar{h}^{*}, t+1}^{R} \text {, }
\end{aligned}
$$

and

$$
\begin{aligned}
& K_{\bar{h}^{*}, t}^{R}=E_{t} \sum_{T=t}^{\infty}(\psi \beta)^{T-t} \frac{u^{\prime}\left(C_{T}\right) P_{t}}{u^{\prime}\left(C_{t}\right) P_{T}} \frac{w_{\bar{h}^{*}, T}^{*}}{w_{\bar{h}^{*}, t}^{*}}\left(\frac{w_{h^{*}, T}^{*} R_{h^{*}, T}}{w_{\bar{h}^{*}, T}^{*} R_{\bar{h}^{*}, T}} \frac{w_{\bar{h}^{*}, t}^{*} R_{\bar{h}^{*}, t}}{w_{h^{*}, t}^{*} R_{h^{*}, t}^{*}}\right)^{1-n} \frac{L_{T}^{*}}{L_{t}^{*}}\left(\frac{R_{\bar{h}^{*}, t}}{R_{\bar{h}^{*}, T}}\right)^{-\epsilon-1} \times \frac{\epsilon}{\epsilon-1} \frac{S_{T}\left(1+i_{T}\right)}{S_{T+1} R_{\bar{h}^{*}, T}} \\
& =\frac{\epsilon}{\epsilon-1} \frac{S_{t}\left(1+i_{t}\right)}{S_{t+1} R_{\bar{h}^{*}, t}}+E_{t} \psi \beta \frac{u^{\prime}\left(C_{t+1}\right) P_{t} w_{\bar{h}^{*}, t+1} L_{t+1}^{*}}{u^{\prime}\left(C_{t}\right) P_{t+1} w_{\bar{h}^{*}, t} L_{t}^{*}}\left(\frac{w_{h^{*}, t+1} w_{\bar{h}^{*}, t} R_{h^{*}, t+1} R_{\bar{h}^{*}, t}}{w_{h^{*}, t} w_{\bar{h}^{*}, t+1} R_{h^{*}, t} R_{\bar{h}^{*}, t+1}}\right)^{1-n}\left(\frac{R_{\bar{h}^{*}, t}}{R_{\bar{h}^{*}, t+1}}\right)^{-\epsilon-1} K_{\bar{h}^{*}, t+1}^{R} .
\end{aligned}
$$

Furthermore, the dynamics of the dispersion stemming from the staggered loan contracts can also be defined by using Equation (64) as

$$
\Delta_{\bar{h}^{*}, t}=(1-\psi)\left[\frac{1-\psi\left(\frac{R_{\bar{h}^{*}, t}}{R_{\bar{h}^{*}, t-1}}\right)^{\epsilon-1}}{1-\psi}\right]^{\frac{\epsilon}{\epsilon-1}}+\psi\left(\frac{R_{\vec{h}^{*}, t}}{R_{\bar{h}^{*}, t-1}}\right)^{\epsilon} \Delta_{\bar{h}^{*}, t-1} .
$$

Similarly, as the optimal condition for $\tilde{R}_{h, t}$, we have

$$
\begin{aligned}
& {\left[\frac{1-\psi\left(\frac{R_{h, t}}{R_{h, t-1}}\right)^{\epsilon-1}}{1-\psi}\right]^{\frac{1}{1-\epsilon}} F_{h, t}^{R}=K_{h, t}^{R},} \\
& F_{h, t}^{R}=1+E_{t} \psi \beta \frac{u^{\prime}\left(C_{t+1}\right) P_{t} w_{h, t+1} L_{t+1}}{u^{\prime}\left(C_{t}\right) P_{t+1} w_{h, t} L_{t}}\left(\frac{w_{h, t} w_{\bar{h}, t+1} R_{h, t} R_{\bar{h}^{*}, t+1}}{w_{h, t+1} w_{\bar{h}, t} R_{h, t+1} R_{\bar{h}^{*}, t}}\right)^{n}\left(\frac{R_{h, t}}{R_{h, t+1}}\right)^{-\epsilon} F_{h, t+1}^{R}, \\
& K_{h, t}^{R}=\frac{\epsilon}{\epsilon-1} \frac{\left(1+i_{t}\right) \exp \left(m_{t}\right)}{R_{h, t}} \\
& +E_{t} \psi \beta \frac{u^{\prime}\left(C_{t+1}\right) P_{t} w_{h, t+1} L_{t+1}}{u^{\prime}\left(C_{t}\right) P_{t+1} w_{h, t} L_{t}}\left(\frac{w_{h, t} w_{\bar{h}, t+1} R_{h, t} R_{\bar{h}^{*}, t+1}}{w_{h, t+1} w_{\bar{h}, t} R_{h, t+1} R_{\bar{h}^{*}, t}}\right)^{n}\left(\frac{R_{h, t}}{R_{h, t+1}}\right)^{-\epsilon-1} K_{h, t+1}^{R},
\end{aligned}
$$




$$
\Delta_{h, t}=(1-\psi)\left[\frac{1-\psi\left(\frac{R_{h, t}}{R_{h, t-1}}\right)^{\epsilon-1}}{1-\psi}\right]^{\frac{\epsilon}{\epsilon-1}}+\psi\left(\frac{R_{h, t}}{R_{h, t-1}}\right)^{\epsilon} \Delta_{h, t-1} .
$$

Foreign Similarly, as the optimal conditions for the loan rate settings by foreign banks, we can derive

$$
\begin{aligned}
& {\left[\frac{1-\psi\left(\frac{R_{\bar{h}, t}}{R_{\bar{h}, t-1}}\right)^{\epsilon-1}}{1-\psi}\right]^{\frac{1}{1-\epsilon}} F_{\bar{h}, t}^{R}=K \bar{h}, t} \\
& F_{\bar{h}, t}^{R}=1+E_{t} \psi \beta \frac{u^{\prime}\left(C_{t+1}^{*}\right) P_{t}^{*} w_{\bar{h}, t+1} L_{t+1}}{u^{\prime}\left(C_{t}^{*}\right) P_{t+1}^{*} w_{\bar{h}, t} L_{t}}\left(\frac{w_{h, t+1} w_{\bar{h}, t} R_{h, t+1} R_{\bar{h}, t}}{w_{h, t} w_{\bar{h}, t+1} R_{h, t} R_{\bar{h}, t+1}}\right)^{1-n}\left(\frac{R_{\bar{h}, t}}{R_{\bar{h}, t+1}}\right)^{-\epsilon} F_{\bar{h}, t+1}^{R}, \\
& K_{\bar{h}, t}^{R}=\frac{\epsilon}{\epsilon-1} \frac{S_{t+1}\left(1+i_{t}\right)}{S_{t} R_{\bar{h}^{*}, t}} \\
& +E_{t} \psi \beta \frac{u^{\prime}\left(C_{t+1}^{*}\right) P_{t}^{*} w_{\bar{h}, t+1} L_{t+1}}{u^{\prime}\left(C_{t}^{*}\right) P_{t+1}^{*} w_{\bar{h}, t} L_{t}}\left(\frac{w_{h, t+1} w_{\bar{h}, t} R_{h, t+1} R_{\bar{h}, t}}{w_{h, t} w_{\bar{h}, t+1} R_{h, t} R_{\bar{h}, t+1}}\right)^{1-n}\left(\frac{R_{\bar{h}, t}}{R_{\bar{h}, t+1}}\right)^{-\epsilon-1} K_{\bar{h}, t+1}^{R}, \\
& \Delta_{\bar{h}, t}=(1-\psi)\left[\frac{1-\psi\left(\frac{R_{\bar{h}, t}}{R_{\bar{h}, t-1}}\right)^{\epsilon-1}}{1-\psi}\right]^{\frac{\epsilon}{\epsilon-1}}+\psi\left(\frac{R_{\bar{h}, t}}{R_{\bar{h}, t-1}}\right)^{\epsilon} \Delta_{\bar{h}, t-1}, \\
& {\left[\frac{1-\psi\left(\frac{R_{h^{*}, t}}{R_{h^{*}, t-1}}\right)^{\epsilon-1}}{1-\psi}\right]^{\frac{1}{1-\epsilon}} F_{h^{*}, t}^{R}=K_{h^{*}, t}^{R}} \\
& F_{h^{*}, t}^{R}=1+E_{t} \psi \beta \frac{u^{\prime}\left(C_{t+1}^{*}\right) P_{t}^{*} w_{h *, t+1} L_{t+1}^{*}}{u^{\prime}\left(C_{t}^{*}\right) P_{t+1}^{*} w_{h^{*}, t} L_{t}^{*}}\left(\frac{w_{h^{*}, t} w_{\bar{h}^{*}, t+1} R_{h^{*}, t} R_{\bar{h}^{*}, t+1}}{w_{h^{*}, t+1} w_{\bar{h}^{*}, t} R_{h^{*}, t+1} R_{\bar{h}^{*}, t}}\right)^{n}\left(\frac{R_{h^{*}, t}}{R_{h^{*}, t+1}}\right)^{-\epsilon} F_{h^{*}, t+1}^{R}, \\
& K_{h^{*}, t}^{R}=\frac{\epsilon}{\epsilon-1} \frac{1+i_{t}^{*}}{R_{h^{*}, t}^{*}} \\
& +E_{t} \psi \beta \frac{u^{\prime}\left(C_{t+1}^{*}\right) P_{t}^{*} w_{h^{*}, t+1} L_{t+1}^{*}}{u^{\prime}\left(C_{t}^{*}\right) P_{t+1}^{*} w_{h^{*}, t} L_{t}^{*}}\left(\frac{w_{h^{*}, t} w_{\bar{h}^{*}, t+1} R_{h^{*}, t} R_{\bar{h}^{*}, t+1}}{w_{h^{*}, t+1} w_{\bar{h}^{*}, t} R_{h^{*}, t+1} R_{\bar{h}^{*}, t}}\right)^{n}\left(\frac{R_{h^{*}, t}}{R_{h^{*}, t+1}}\right)^{-\epsilon-1} K_{h^{*}, t+1}^{R},
\end{aligned}
$$


and

$$
\Delta_{h^{*}, t}=(1-\psi)\left[\frac{1-\psi\left(\frac{R_{h^{*}, t}}{R_{h^{*}, t-1}}\right)^{\epsilon-1}}{1-\psi}\right]^{\frac{\epsilon}{\epsilon-1}}+\psi\left(\frac{R_{h^{*}, t}}{R_{h^{*}, t-1}}\right)^{\epsilon} \Delta_{h^{*}, t-1},
$$

where we use Equation (49).

\section{A.3 Aggregation}

A.3.1 Domestic. Output $y_{t}(f)$ produced by the domestic firm $f$ must be consumed by either domestic or foreign consumer ${ }^{16}$ :

$$
y_{t}(f)=c_{t}(f)+c_{t}^{*}(f) .
$$

By integrating over all domestic firms, this can be rewritten as

$$
Y_{t}=\exp \left(z_{t}\right) L_{t}=\Delta_{H, t} \phi\left(\frac{P_{H, t}}{P_{t}}\right)^{-1} C_{t}+\Delta_{H, t}^{*}(1-\phi)\left(\frac{P_{H, t}^{*}}{P_{t}^{*}}\right)^{-1} C_{t}^{*},
$$

where we use Equations (38) and (46). Following Yun (2005), we define the price dispersion terms as

$$
\Delta_{H, t} \equiv \int_{0}^{1}\left[\frac{p_{t}(f)}{P_{H, t}}\right]^{-\sigma} d f
$$

and

$$
\Delta_{H, t}^{*} \equiv \int_{0}^{1}\left[\frac{p_{t}^{*}(f)}{P_{H, t}^{*}}\right]^{-\sigma} d f .
$$

Similarly, we define the loan rate dispersion as

$$
\Delta_{h, t} \equiv \frac{1}{n} \int_{0}^{n}\left[\frac{R_{t}(h)}{R_{h, t}}\right]^{-\epsilon} d h,
$$

and

$$
\Delta_{\bar{h}, t} \equiv \frac{1}{1-n} \int_{n}^{1}\left[\frac{R_{t}(\bar{h})}{R_{\bar{h}, t}}\right]^{-\epsilon} d h .
$$

Thus, Equations (5) and (6) are now expressed as

$$
l_{h, t}=L_{h, t} \Delta_{h, t},
$$

and

$$
l_{\bar{h}, t}=L_{\bar{h}, t} \Delta_{\bar{h}, t} .
$$

\footnotetext{
${ }^{16}$ Since we assume two symmetric countries, we can ignore the weights on per capita variables.
} 
A.3.2 Foreign. We have similar definitions and conditions for the foreign country:

$$
\begin{aligned}
& Y_{t}^{*}=\exp \left(z_{t}\right) L_{t}^{*}=\Delta_{F, t}(1-\phi)\left(\frac{P_{F, t}}{P_{t}}\right)^{-1} C_{t}+\Delta_{F, t}^{*} \phi\left(\frac{P_{F, t}^{*}}{P_{t}^{*}}\right)^{-1} C_{t}^{*}, \\
& \Delta_{F, t} \equiv \int_{0}^{1}\left[\frac{p_{t}\left(f^{*}\right)}{P_{F, t}}\right]^{-\sigma} d f^{*}, \\
& \Delta_{F, t}^{*} \equiv \int_{0}^{1}\left[\frac{p_{t}^{*}\left(f^{*}\right)}{P_{F, t}}\right]^{-\sigma} d f^{*}, \\
& \Delta_{h^{*}, t} \equiv \frac{1}{n} \int_{0}^{n}\left[\frac{R_{t}^{*}\left(h^{*}\right)}{R_{h^{*}, t}^{*}}\right]^{-\epsilon} d h^{*}, \\
& \Delta_{\bar{h}^{*}, t} \equiv \frac{1}{1-n} \int_{n}^{1}\left[\frac{R_{t}\left(\bar{h}^{*}\right)}{R_{\bar{h}^{*}, t}^{*}}\right]^{-\epsilon} d \bar{h}^{*}, \\
& l_{h^{*}, t}=L_{h^{*}, t} \Delta_{h^{*}, t}
\end{aligned}
$$

and

$$
l_{\bar{h}^{*}, t}=L_{\bar{h}^{*}, t} \Delta_{\bar{h}^{*}, t}
$$

\section{A.4 Equilibrium}

The model consists of Equations (17), (18), (33), (35)-(39), (41), (43)-(49), (51)-(53), (56)-(63), (65)-(67), (69)-(76), (79)-(95), (97)-(101). We de-trend all variables in above equations by

$$
\begin{aligned}
& \pi_{t}=\frac{P_{t}}{P_{t-1}}, \pi_{t}^{*}=\frac{P_{t}^{*}}{P_{t-1}^{*}}, p_{H, t}=\frac{P_{H, t}}{P_{t}}, p_{F, t}=\frac{P_{F, t}}{P_{t}}, p_{H, t}^{*}=\frac{P_{H, t}^{*}}{P_{t^{*}}}, p_{F, t}^{*}=\frac{P_{F, t}^{*}}{P_{t}}, \\
& e_{t}=\frac{S_{t} P_{t}^{*}}{P_{t}}, \pi_{H, t}=\frac{P_{H, t}}{P_{H, t-1}}, \pi_{H, t}^{*}=\frac{P_{H, t}^{*}}{P_{H, t-1}^{*}}, \pi_{F, t}=\frac{P_{F, t}}{P_{F, t-1}} \pi_{F, t}^{*}=\frac{P_{F, t}^{*}}{P_{F, t-1}^{*}}, S_{t}=\frac{S_{t}}{S_{t-1}},
\end{aligned}
$$

In addition, we assume

$$
u\left(C_{t}\right)=\frac{C_{t}^{1-v}}{1-v}, v\left(l_{t}\right)=\frac{l_{t}^{1+\eta}}{1+\eta},
$$

and add several definitions as

$$
\begin{aligned}
& \pi_{H, t}=\frac{P_{H, t}}{P_{H, t-1}}=\frac{p_{H, t}}{p_{H, t-1}} \pi_{t}, \\
& \pi_{H, t}^{*}=\frac{P_{H, t}^{*}}{P_{H, t-1}^{*}}=\frac{p_{H, t}^{*}}{p_{H, t-1}^{*}} \pi_{t}^{*}, \\
& \pi_{F, t}=\frac{P_{F, t}}{P_{F, t-1}}=\frac{p_{F, t}}{p_{F, t-1}} \pi_{t}, \\
& \pi_{F, t}^{*}=\frac{P_{F, t}^{*}}{P_{F, t-1}^{*}}=\frac{p_{F, t}^{*}}{p_{F, t-1}^{*}} \pi_{t}^{*},
\end{aligned}
$$




\section{A.5 Linearized model}

We log-linearize the equilibrium conditions around the deterministic steady states. Particularly, in our benchmark calibration, namely when $\eta=0$, we can derive the log-linearized model as in Equations (19)-(29).

\section{B Impulse response}

We show the impulse response to a loan rate shock for the loan rate set by the home local bank to a home firm. Fig. B1 shows the case for the model with a flexible loan rate and flexible goods price settings, and corresponds to the third row of Table 3. Fig. B2 shows the case for the model with a sticky loan rate and flexible goods price settings, and corresponds to the seventh row of Table 3. Fig. B3 shows the case for the model with a flexible loan rate and sticky goods price settings, and corresponds to the third row of Table 4. Fig. B4 shows the case for a model with a sticky loan rate and sticky goods price settings, and corresponds to the seventh row of Table 4.
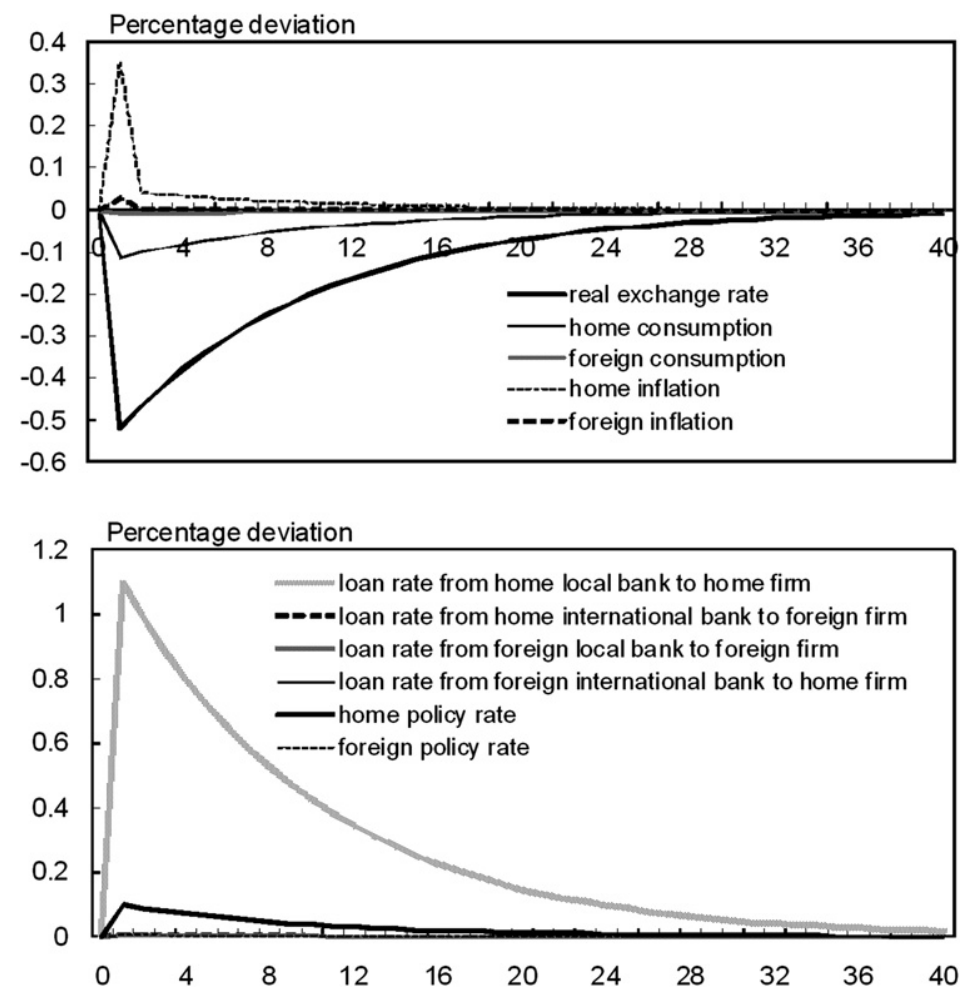

Fig. B1. Impulse response to a loan rate shock for the loan rate set by the home local bank for a home firm in the model with a flexible loan rate and flexible goods price settings. 

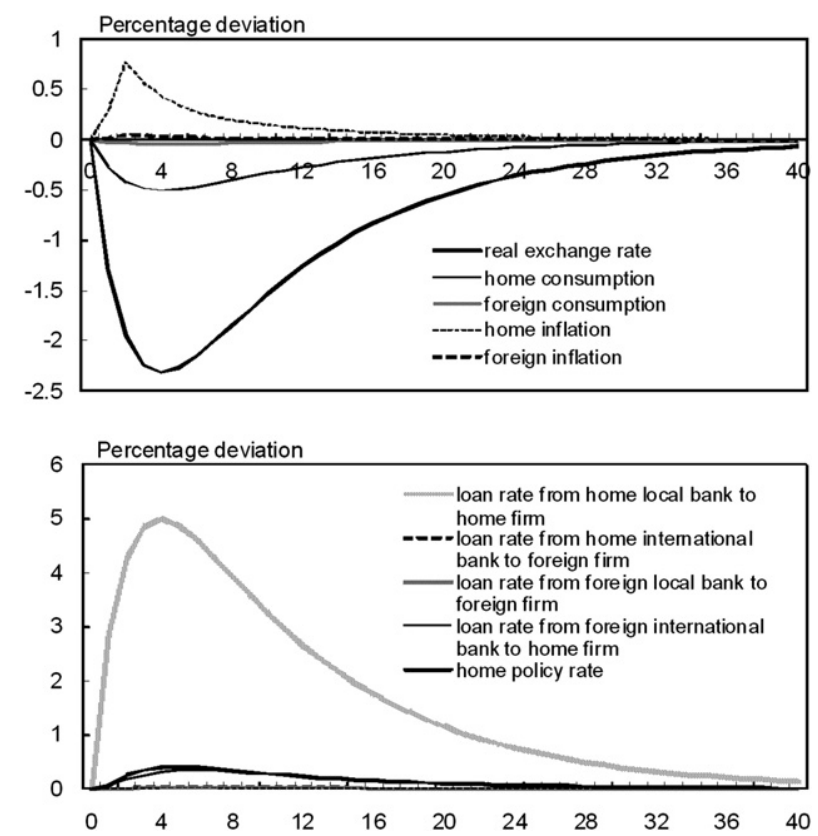

Fig. B2. Impulse response to a loan rate shock for the loan rate set by the home local bank for a home firm in the model with a sticky loan rate and flexible goods price settings.
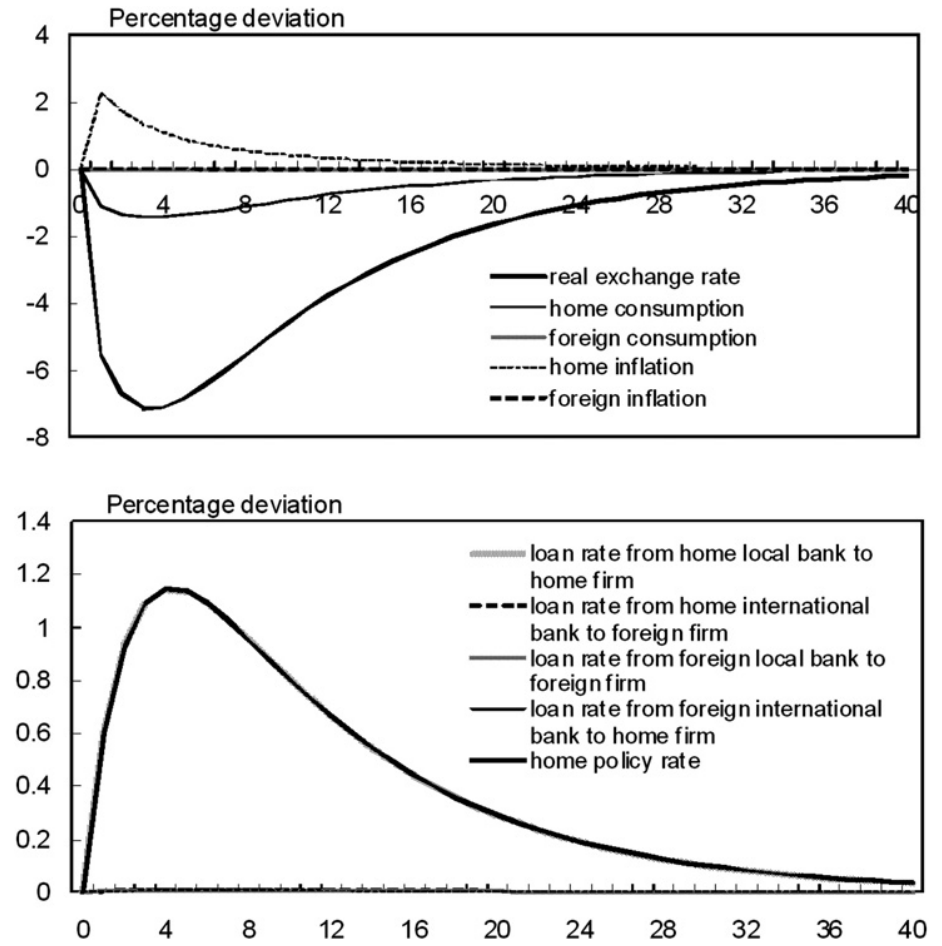

Fig. B3. Impulse response to a loan rate shock for the loan rate set by the home local bank for a home firm in the model with a flexible loan rate and sticky goods price settings. 

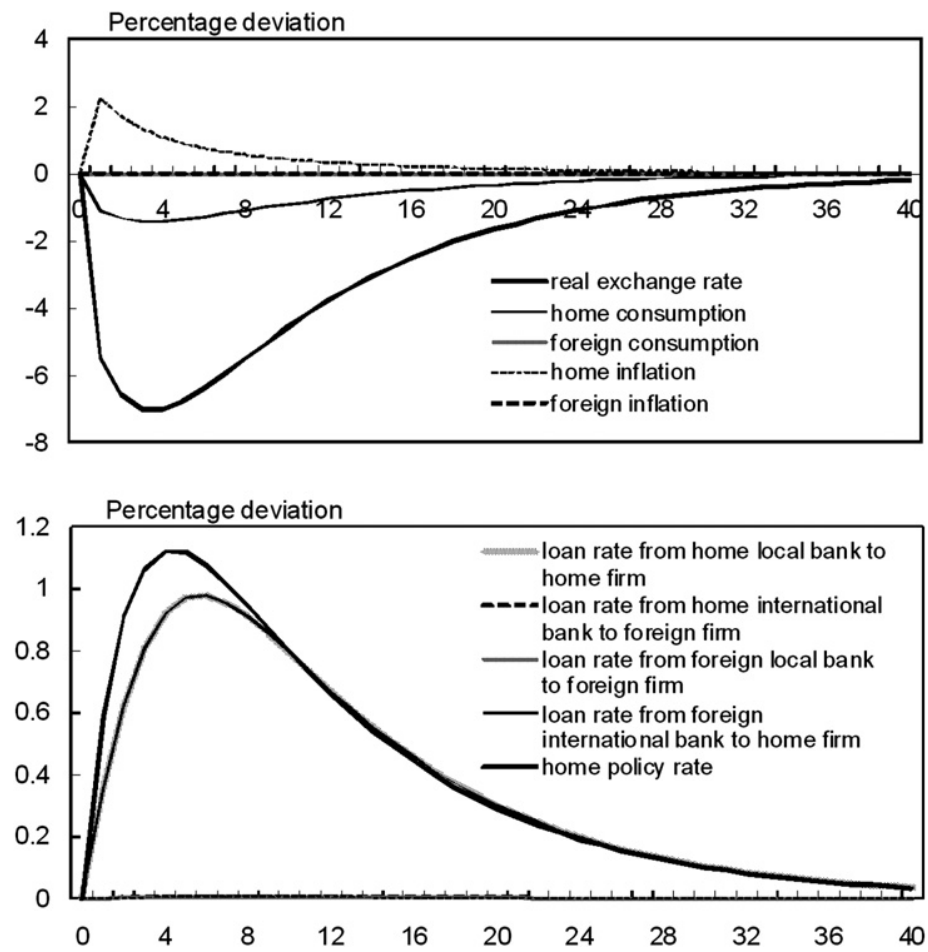

Fig. B4. Impulse response to a loan rate shock for the loan rate set by the home local bank for a home firm in the model with a sticky loan rate and sticky goods price settings.

\section{References}

Bank of Japan, 2007. Financial System Report Bank of Japan Reports and Research Papers, March.

Bank of Japan, 2009. Financial System Report Bank of Japan Reports and Research Papers, March.

Benigno, Gianluca, 2004. Real exchange rate persistence and monetary policy rules. Journal of Monetary Economics 51 (3), $473-$ 502.

Benigno, Pierpaolo, 2004. Optimal monetary policy in a currency area. Journal of International Economics 63 (2), $293-320$.

Berger, Allen N, Udell, Gregory F, 1992. Some evidence on the empirical significance of credit rationing. Journal of Political Economy 100 (5), 1047-1077.

Bergin, Paul R., Feenstra, Robert C., 2000. Staggered price setting, Translog preferences, and endogenous persistence. Journal of Monetary Economics 45 (3), 657-680.

Bernanke, Ben S., Gertler, Mark, Gilchrist, Simon, 1999. The financial accelerator in a quantitative business cycle framework. In: Taylor, John B., Woodford, Michael (Eds.), Handbook of Macroeconomics. Handbook of Macroeconomics, vol. 1. Elsevier, pp. 1341-1393.

Cúrdia, Vasco, Woodford, Michael, 2010. Credit spreads and monetary policy. Journal of Money, Credit and Banking 42 (s1), 3-35.

Calvo, Guillermo A, 1983. Staggered prices in a utility-maximizing framework. Journal of Monetary Economics 12 (3), 383-398.

Chari, V.V., Kehoe, Patrick J, McGrattan, Ellen R, 2002. Can sticky price models generate volatile and persistent real exchange rates? Review of Economic Studies 69 (3), 533-563.

Cheung, Yin-Wong, Lai, Kon S., 2000. On the purchasing power parity puzzle. Journal of International Economics 52 (2), $321-$ 330.

Christiano, Lawrence J., Motto, Roberto, Rostagno, Massimo, 2008. Shocks, structures or monetary policies? The euro area and US after 2001. Journal of Economic Dynamics and Control 32 (8), 2476-2506.

Chrsitiano, Lawrence J., Vigfusson, Robert J., 2003. Maximum likelihood in the frequency domain: the importance of time-toplan. Journal of Monetary Economics 50 (4), 789-815

Eichenbaum, Martin, Evans, Charles L, 1995. Some empirical evidence on the effects of shocks to monetary policy on exchange rates. The Quarterly Journal of Economics 110 (4), 975-1009.

Faust, Jon, Rogers, John H., 2003. Monetary policy's role in exchange rate behavior. Journal of Monetary Economics 50 (7), $1403-$ 1424.

Gadanecz, Blaise, 2004. The syndicated loan market. BIS Quarterly Review. 
Gambacorta, Leonardo, 2008. How do banks set interest rates? European Economic Review 52 (5), $792-819$.

Gerali, Andrea, Neri, Stefano, Sessa, Luca, Signoretti, Federico M., 2010. Credit and banking in a DSGE model of the euro area. Journal of Money, Credit and Banking 42 (s1), 107-141.

Graham, Liam, Wright, Stephen, 2007. Nominal debt dynamics, credit constraints and monetary policy. The B.E. Journals of Macroeconomics 7 (1).

Gropp, Reint, Kok Sorensen, Christoffer, Lichtenberger, Jung-Duk, 2007. The Dynamics of Bank Spreads and Financial Structure. Working Paper Series 714. European Central Bank.

Gropp, Reint Eberhard, Kashyap, Anil K., 2009. A New Metric for Banking Integration in Europe. NBER Working Paper 14735. National Bureau of Economic Research.

Gust, Christopher, Vigfusson, Robert, 2009. The power of long-run structural VARs (Discussion paper).

Kobayashi, Teruyoshi, 2008. Incomplete interest rate pass-through and optimal monetary policy. International Journal of Central Banking 4 (3), 77-118.

Lane, Philip R., Milesi-Ferretti, Gian Maria, 2007. The external wealth of national mark II. Journal of International Economics 73 (2), 223-250.

Lane, Philip R., Milesi-Ferretti, Gian Maria, 2008. The drivers of financial globalization. American Economic Review 98 (2), $327-$ 332.

Lubik, Thomas A., Schorfheide, Frank, 2005. A Bayesian look at new open economy macroeconomics. In: Gertler, Mark, Rogoff, Kenneth (Eds.), NBER Macroeconomics Annual 2005, vol. 20. MIT Press, Cambridge.

Mandelman, Federico S., 2010. Business cycles and monetary regimes in emerging economies: a role for a monopolistic banking sector. Journal of International Economics 81 (1), 122-138.

Marston, Richard C, 1995. International Financial Integration: A Study of Interest Differentials Between the Major Industrial Countries. Cambridge University Press.

McGuire, Patrick, Tarashev, Nikola, 2006. Tracking international bank Flows. BIS Quarterly Review 27 (4).

Neumeyer, Pablo A., Perri, Fabrizio, 2005. Business cycles in emerging economies: the role of interest rates. Journal of Monetary Economics 52 (2), 345-380.

Rotemberg, Julio J., Woodford, Michael, 1997. An optimization-based econometric framework for the evaluation of monetary policy. NBER Macroeconomics Annual 12, 297-346.

Sander, Harald, Kleimeier, Stefanie, 2004. Convergence in euro zone retail banking. Journal of International Money and Finance 23 (3), 461-492.

Schmitt-Grohé, Stephanie, Uribe, Martin, 2006. Comparing Two Variants of Calvo-Type Wage Stickiness. NBER Working Paper 12740. National Bureau of Economic Research.

Schmitt-Grohé, Stephanie, Uribe, Martin, 2007. Optimal simple and implementable monetary and Fiscal rules. Journal of Monetary Economics 54 (6), 1702-1725.

Slovin, Myron B, Sushka, Marie Elizabeth, 1983. A model of the commercial loan rate. Journal of Finance 38 (5), $1583-1596$.

Sorensen, Christoffer Kok, Werner, Thomas, 2006. Bank Interest Rate Pass-Through in the Euro Area: A Cross Country Comparison. Working Paper Series 580. European Central Bank.

Steinsson, Jón, 2008. The dynamic behavior of the real exchange rate in sticky price models. American Economic Review 98 (1), 519-533.

Taylor, John B, 1993. Discretion versus Policy Rules in Practice. In: Carnegie-Rochester Conference Series on Public Policy, vol. 39 195-214.

Teranishi, Yuki, 2008. Optimal Monetary Policy under Staggered Loan Contracts. IMES Discussion Paper Series 08-E-08. Institute for Monetary and Economic Studies, Bank of Japan.

Uribe, Martín, Yue, Vivian Z., 2006. Country spreads and emerging countries: who drives whom? Journal of International Economics 69 (1), 6-36.

Yun, Tack, 1996. Nominal price rigidity, money supply endogeneity, and business cycles. Journal of Monetary Economics 37 (23), 345-370.

Yun, Tack, 2005. Optimal monetary policy with relative price distortions. American Economic Review 95 (1), 89-109. 